\title{
Avaliação de Metodologias de Envelhecimento em Painéis de Partículas de Bagaço de Cana-de-açúcar para Aplicação em Sistemas Construtivos
}

\author{
Nubia Mireya Garzón Barrero \\ Juliano Fiorelli \\ João Adriano Rossignolo \\ Holmer Savastano Junior
}

\section{Resumo}

O presente trabalho tem por objetivo apresentar os conceitos relacionados à durabilidade, aos mecanismos e aos agentes de degradação que interferem no desempenho de painéis particulados, assim como as principais metodologias usadas para a sua avaliação. Além disso, o trabalho também pretende avaliar o desempenho físico-mecânico e a durabilidade de painéis de partículas de bagaço de cana-de-açúcar com resina bicomponente à base de óleo de mamona e compará-los com painéis de partículas de madeira comerciais (Medium Density Particleboard - MDP) e resina de uréia-formaldeído. Para tanto, os painéis fabricados com partículas de bagaço de cana-de-açúcar (BCP) e os painéis comerciais de partículas de madeira (MDP) foram revestidos superficialmente com resina poliuretana bicomponente à base de óleo de mamona. Finalmente, são apresentados os resultados do acompanhamento das propriedades mecânicas antes e após os ensaios de envelhecimento por exposição natural, de envelhecimento acelerado e de avaliação das condições isoladas de degradação.

Palavras-Chave: Resíduos agroindustriais, durabilidade, envelhecimento acelerado, painéis particulados, mamona. 


\section{Introdução}

Atualmente, com a crescente preocupação mundial com a sustentabilidade, a utilização dos recursos naturais renováveis tem sido uma temática discutida pelos países desenvolvidos e em desenvolvimento. Esses recursos representam uma fonte alternativa de grande potencial econômico, tornando-se vital para a sobrevivência das indústrias em um mercado globalizado e competitivo. Segundo Campos (2005), para que haja desenvolvimento sustentável, é fundamental atender as necessidades básicas das pessoas, oferecer condições de concretizar as aspiraçóes por uma vida melhor, manter os padróes de consumo dentro do limite das possibilidades ecológicas a que todos possam aspirar, garantir o crescimento econômico em regiôes onde tais necessidades se limitam no âmbito único de exploração, conservar as espécies vegetais, minimizar os impactos adversos sobre a qualidade do ar, da água e de outros elementos naturais, preservando a integridade global do ecossistema.

A disposição final dos resíduos sólidos gerados na agricultura e nas atividades de produção industrial apresenta problemas em países em desenvolvimento. As maiores quantidades de resíduos gerados de origem agroindustrial são bagaço de cana-de-açúcar, casca de arroz, fibra de coco e fibra de juta, entre outros (MADURWAR et al., 2013). A reutilização desses resíduos como materiais renováveis para a construçáo civil pode apresentar uma solução não só para resolver problemas de poluição ambiental, mas também para diminuir os problemas de alto custo de materiais para a construção.

As indústrias de painéis aglomerados e de fibras, no Brasil, utilizam preferencialmente cavacos de madeira de reflorestamento provenientes de Pinus e de algumas espécies de eucalipto, tendo em vista o melhor controle de homogeneidade da matéria-prima e consequentemente a melhor qualidade do produto final. Porém, os materiais lignocelulósicos provenientes de resíduos agroindustriais vêm sendo uma alternativa para fabricação de painéis (SARTORI, 2012), haja vista o crescente aumento da produção agrícola. A agroindústria brasileira apresenta inúmeros resíduos lignocelulósicos com potencialidades de aproveitamento para fabricação de novos materiais, por exemplo, a fibra de coco (BRITO et al., 2004, PASSOS, 2005 e FIORELLI et al., 2012), a casca de amendoim (PABLO et al., 1975; CARASCHI et al., 2009; GATANI, 2014 ) e o bagaço de cana-de-açúcar (WIDYORINI et al., 2005; CONTRERAS et al., 2006; SILVA et al., 2008; CARASCHI et al ., 2009; BATTISTELLE et al., 2009 e FIORELLI et al., 
2013). A utilizaçáo de resíduos agroindustriais, como o bagaço de cana-deaçúcar, em conjunto com os polímeros naturais, para produção de elementos construtivos para a construção civil, apresenta-se como uma oportunidade de agregar valor aos resíduos da indústria sucroalcooleira brasileira e introduzir no mercado da construção civil materiais mais sustentáveis. No entanto, esses materiais deverão garantir desempenho físico-mecânico satisfatório e durabilidade, conforme os requisitos técnicos e as necessidades do usuário. Além do aproveitamento do caldo da cana-de-açúcar para a produção de etanol e açúcar, o bagaço pode ser utilizado para cogeração de energia limpa, por meio de processos de combustão e de gaseificação. No entanto, o bagaço de cana-de-açúcar também pode ser reaproveitado para produção de compósitos particulados.

O presente capítulo apresenta os conceitos relacionados com a durabilidade e o desempenho dos painéis particulados. $\mathrm{O}$ estudo se justifica pela necessidade de se identificarem os agentes e os mecanismos de degradação que podem afetar o desempenho físico-mecânico dos compósitos de bagaço de cana-de-açúcar aglomerado com resina bicomponente poliuretana à base de óleo de mamona e de madeira com resina ureia-formaldeído. A partir dessa temática, almejase compreender o comportamento do material em determinadas condiçóes de exposição e contribuir para avançar no desenvolvimento de produtos sustentáveis que apresentem uma boa qualidade para aplicaçóes práticas de engenharia. Além disso, apresentam-se os resultados obtidos em diferentes metodologias de avaliação de durabilidade, em laboratório e em exposição natural, visando a identificar sua viabilidade técnica como componente construtivo.

\section{Painéis de Partículas de Madeira}

A tecnologia de produção de painéis de partículas aglomeradas desenvolveuse principalmente após a Segunda Guerra Mundial, em decorrência da escassez da matéria-prima e, também, por conta da redução das perdas ocorridas tanto na indústria madeireira como na exploração florestal (MENDES et al., 2003). Os painéis de madeira surgiram da necessidade de amenizar as variaçóes dimensionais da madeira maciça, diminuir seu peso e custo e manter as propriedades isolantes, térmicas e acústicas da matéria prima original. Adicionalmente, suprem uma necessidade reconhecida no uso da madeira serrada, com a ampliação da sua superfície útil, através da expansão de uma de suas dimensóes (a largura), para otimizar a sua aplicação (IPT, 2003). 
De acordo com a norma NBR 14810 (2002), painéis de partículas de madeira ou MDP (Medium Density Particleboard), ou PPMD (Painel de Partículas de Média Densidade) têm espessura entre 3 a $50 \mathrm{~mm}$ e são constituídos por partículas aglomeradas de madeira, resinas naturais ou sintéticas e termofixas, cuja mistura é submetida à pressão e ao calor. A Figura 1 mostra o esquema de classificação dos painéis, baseando-se em algumas variáveis, conforme Iwaiwiri et al. (2003).

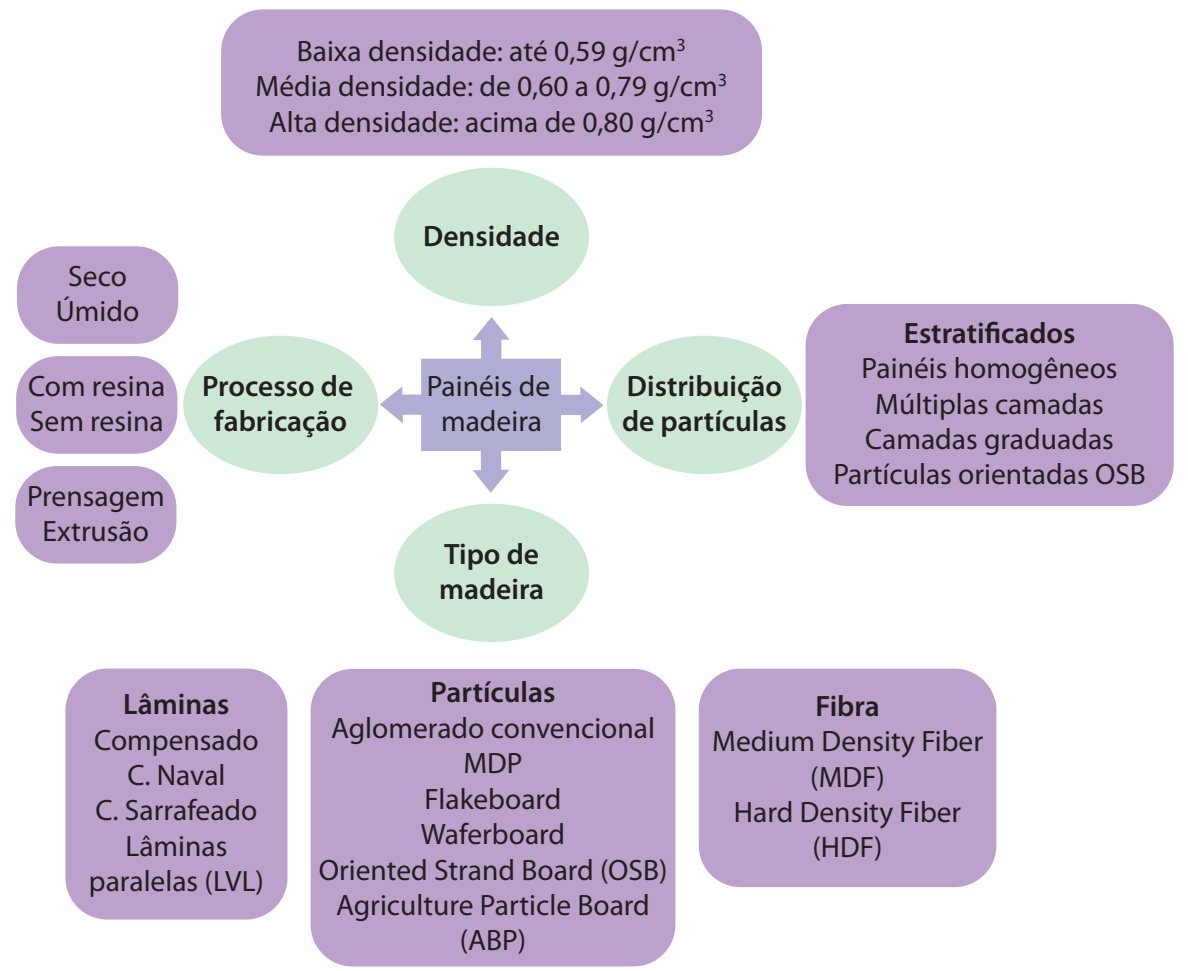

Figura 1. Classificação dos painéis de madeira. Fonte: adaptado de Iwaikiri (2003).

\section{Resinas para Fabricação de Painéis}

A resina é usada na fabricação dos painéis para aglutinar as partículas de madeira que compóem o painel, conferindo-lhe forma, sustentação e resistência (ZENID, 2007). Atualmente, $70 \%$ de todos os painéis fabricados no mundo levam algum tipo de resina (aglomerante) e, deste total, a grande maioria utiliza resinas sintéticas. Em relação às resinas para fabricação de painéis, a 
resina à base de formaldeído em solução aquosa é utilizada frequentemente pela indústria, em razão do baixo custo. Segundo Melo (2009), 90\% de todos os painéis aglomerados produzidos no mundo utilizam resinas de ureiaformaldeído (UF). A Tabela 1 apresenta as características das resinas utilizadas na fabricação de painéis de partículas.

Tabela 1. Características das resinas empregadas na fabricação de painéis de partículas.

\begin{tabular}{|c|c|}
\hline Tipo de Resina & Aplicações \\
\hline $\begin{array}{l}\text { Fenol- } \\
\text { formaldeído } \\
\text { (resinas PF) }\end{array}$ & $\begin{array}{l}\text { Fabricação de produtos que exigem algum grau durabilidade } \\
\text { de exposição exterior, por exemplo, OSB, de contraplacado de } \\
\text { madeira macia, e tapume. Exigem tempos de prensa mais longos } \\
\text { e temperaturas mais altas do que as resinas de ureia-formaldeído. } \\
\text { Os produtos que usam resinas PF (muitas vezes referidos como } \\
\text { compostos fenólicos) podem apresentar estabilidade dimensional } \\
\text { reduzida por causa de teores de umidade mais baixos nos produtos } \\
\text { acabados. A cor escura inerente de resinas PF pode torná-las } \\
\text { inadequadas para aplicações de produtos decorativos, tais como } \\
\text { painéis e mobiliário. }\end{array}$ \\
\hline $\begin{array}{l}\text { Ureia-formaldeído } \\
\text { (UF) }\end{array}$ & $\begin{array}{l}\text { Fabricação de produtos em que a uniformidade dimensional e lisura } \\
\text { de superfície são de interesse primário, por exemplo, aglomerado } \\
\text { e MDF. As resinas são projetadas para aplicações interiores. Podem } \\
\text { ser curadas por meio de processos em temperatura ambiente e até } \\
150^{\circ} \mathrm{C} \text {. A pressão e a temperatura, às vezes, podem ser moderadas em } \\
\text { conformidade ao processo. Resinas de ureia-formaldeído são mais } \\
\text { econômicas do que as resinas PF e são as mais amplamente utilizadas } \\
\text { para produtos compósitos de madeira, }\end{array}$ \\
\hline $\begin{array}{l}\text { Melamina- } \\
\text { formaldeído (MF) }\end{array}$ & $\begin{array}{l}\text { Laminados decorativos, revestimento de papel. São geralmente mais } \\
\text { caras do que as resinas PF. }\end{array}$ \\
\hline $\begin{array}{l}\text { Di-isocianato de } \\
\text { difenilmetano } \\
\text { (MDI) }\end{array}$ & $\begin{array}{l}\text { Normalmente utilizada na fabricação de produtos compósitos de } \\
\text { madeira; } \\
\text { MDI é usada principalmente na produção de OSB. As instalações } \\
\text { que usam MDI devem tomar precaução especial com medidas de } \\
\text { segurança ao trabalhador. }\end{array}$ \\
\hline
\end{tabular}

Fonte. Adaptado de Youngquist (1999).

No entanto, existe a tendência mundial para o uso de produtos biodegradáveis, não poluentes e originados de fontes renováveis. $\mathrm{O}$ óleo de mamona ou óleo de rícino, conhecido internacionalmente como castor oil, 
é extraído de uma planta conhecida no Brasil como mamona ou caturra. É uma planta da família das Euforbiáceas, abundantemente encontrada em regiôes tropicais e subtropicais. A partir do óleo de mamona, é possível sintetizar poliois e pré-polímeros com diferentes características que, ao serem misturados, originam poliuretanas. (SILVA et al., 2013).

A resina poliuretana (PU) à base de óleo de mamona apresenta-se como uma alternativa aos adesivos à base de formaldeído utilizados na produçấo de painéis de madeira, prevenindo inconvenientes relacionados à origem não renovável e à emissão de poluentes. Além disso, obtém-se a redução do consumo de energia, devido a menores temperaturas durante a prensagem dos painéis (BERTOLINI et al., 2013).

\section{Durabilidade de Painéis de Madeira}

Conforme as normas ABNT NBR 15575 -2013 e ASTM E 632-1996, são descritos alguns conceitos relacionados com a durabilidade e o desempenho dos materiais e dos componentes construtivos. A Figura 2 apresenta um esquema com os parâmetros necessários para avaliar o desempenho global de um material ou componente, baseando-se na norma ABNT NBR 15575 -2013.

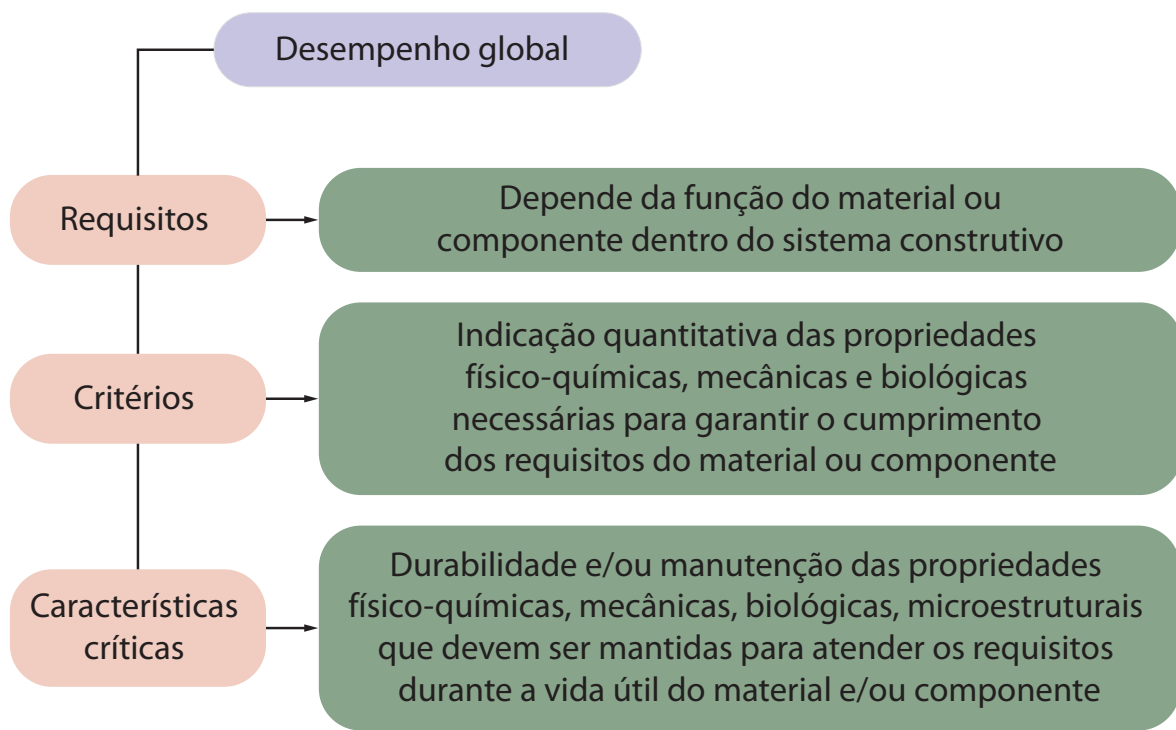

Figura 2. Esquema com os parâmetros necessários para avaliar o desempenho global de um material ou componente. Baseado na norma ABNT NBR 15575 $-2013$. 
- Agente de degradaçáo: Tudo aquilo que age sobre um sistema, contribuindo para reduzir seu desempenho.

- Mecanismos de degradaçáo: São as formas como os agentes de degradação causam as mudanças (físicas ou químicas), que conduzem ao detrimento de uma ou mais propriedades pela açáo dos fatores de degradação no material.

- Degradação: Redução do desempenho devido à atuação de um ou vários agentes de degradação.

- Desempenho: Comportamento em uso de uma edificação ou de seus sistemas.

- Durabilidade: Capacidade da edificação ou de seus sistemas de desempenhar suas funçôes ao longo do tempo e sob condiçóes de uso e manutenção especificadas no manual de uso, operação e manutençáo. O termo durabilidade é comumente utilizado para expressar a condição em que a edificação ou seus sistemas mantêm seu desempenho requerido durante sua vida útil.

\subsection{Agentes ou Fatores de Deterioração}

Agentes de degradação são definidos como ações físicas, químicas, ambientais ou biológicas, bem como seus mecanismos e os efeitos que causam em um material ou componente. Vale ressaltar a ação conjunta entre os agentes como fator importante na previsão da degradação do material. Dentre os vários agentes de degradação, a água é um dos mais importantes (JOHN, 1997). Sua ação nos diferentes estados: líquido, na forma de chuva, vapor na forma de umidade, sólido na forma de gelo pode contribuir para degradaçáo de vários materiais aplicados na construção civil. Outros agentes de degradação importantes são a temperatura e a radiação solar (ultravioleta), que podem ocasionar transformaçôes físicas, químicas, micro e macroestruturais. Os fatores ambientais e, notadamente, a degradação fotoquímica, podem ser designados pela palavra weathering. A Figura 3 apresenta, com base nas diretrizes estabelecidas pela norma ASTM E 632-82, um esquema com os principais fatores que influenciam a durabilidade de um material ou elemento construtivo. 


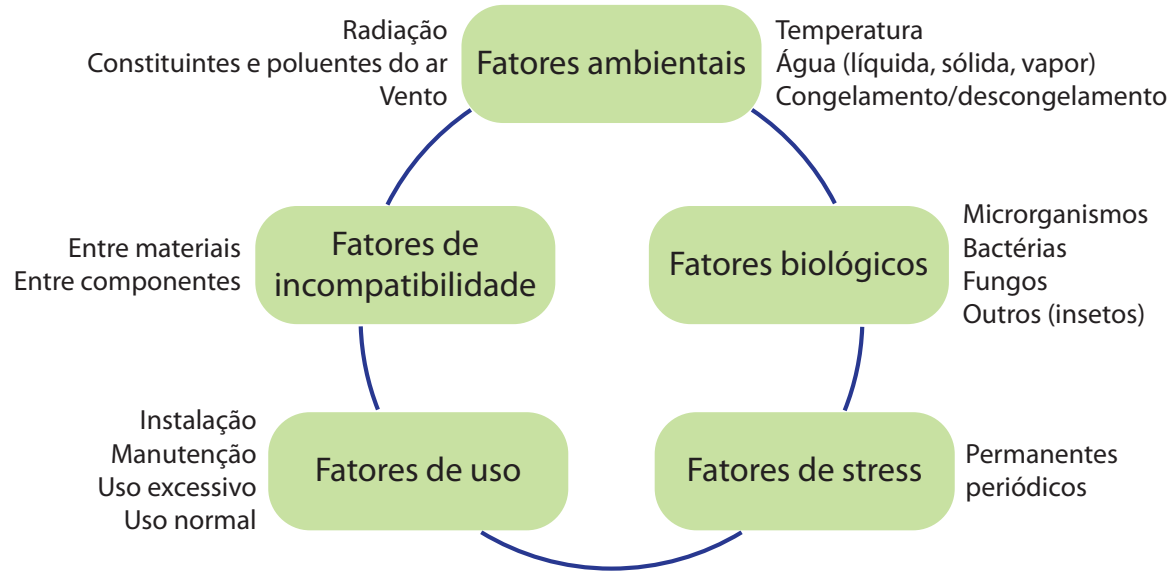

Figura 3. Fatores ou agentes de degradação que influenciam a durabilidade dos materiais. Baseado na norma ASTM E 632-96.

\subsection{Mecanismos de Degradação}

Os mecanismos de degradação são responsáveis pela ocorrência de mudanças nas propriedades físicas e mecânicas. Esses mecanismos podem ser definidos em vários níveis: os associados à degradaçáo física do material, química ou biológica.

\subsubsection{Mecanismos de Degradação Associados aos Fatores Ambientais}

A madeira, como outras substâncias orgânicas, pode sofrer alteraçóes no desempenho e na durabilidade por ação de fatores ambientais associados com a radiação solar, temperatura, precipitação e outras formas de ação da água como congelamento, degelo, umidade, componentes normais do ar, poluentes do ar e vento. Stark et al. (2004) e Fabiyi et al. (2008) afirmam que fatores ambientais podem gerar mudanças na cor e na aparência da madeira. Essa mudança é basicamente uma reação de superfície. A penetração da luz nas capas de madeira é inferior a 75 micrometros, quando se trata da luz UV, e equivalente a 200 micrometros, quando se trata de luz visível. Entretanto, a mudança de cor pode afetar mais profundamente a madeira, devido a reaçóes derivadas da foto-oxidação, o que resulta visivelmente em: a) mudança na cor e perda de brilho; b) aumento da rugosidade; c) laminação, 
rachaduras e gretas; d) escamação-descamação; e) amarelamento. A quantidade e o tipo de deterioraçáo que um material pode apresentar dependem da sua susceptibilidade espectral, definida como a medida do dano causado por energia luminosa, o qual varia de acordo com os comprimentos de onda da luz (curta ou longa).

A água atua também como um fator degradador. Segundo Stark (2006), a água acelera a reação de oxidação e causa o inchamento da fibra de madeira. A degradação dos componentes hidrofóbicos (tal como a lignina) na superfície do compósito conduz ao aumento das quantidades de celulose (componente hidrofílico) na superfície, o que faz com que o polímero-madeira seja mais suscetível à absorção de umidade. A madeira exposta à água salgada tende a absorver essa água e, em ciclos repetidos de molhagem e secagem, as fibras de madeira próximas da superfície apresentarão maior concentração de sal nas células lumens. Essas células podem explodir se absorverem muito sal. Embora o efeito global sobre as propriedades da madeira seja mínimo, as fibras de ruptura podem acumular-se na superfície de madeira, criando uma aparência difusa.

\subsubsection{Mecanismos de Degradação Associados aos Fatores Biológicos}

A madeira é um material orgânico e, por essa razão, pode ser atacada e decomposta por insetos, fungos e bactérias em um processo denominado de biodeterioração, caracterizado pela colonização de insetos, fungos e bactérias nas células e tecidos, causando alteraçôes na estrutura anatômica e propriedades químico-físico-mecânicas (BRAZOLIN, 2009). Desse modo, a degradação biológica de resíduos orgânicos pode ser entendida como resultado da ação de microrganismos que utilizam esse material como substrato para o seu crescimento e desenvolvimento. A Figura 4 ilustra os tipos de fungos que utilizam como alimento a madeira (xilófagos) e os tipos de deterioraçáo causada por eles. 


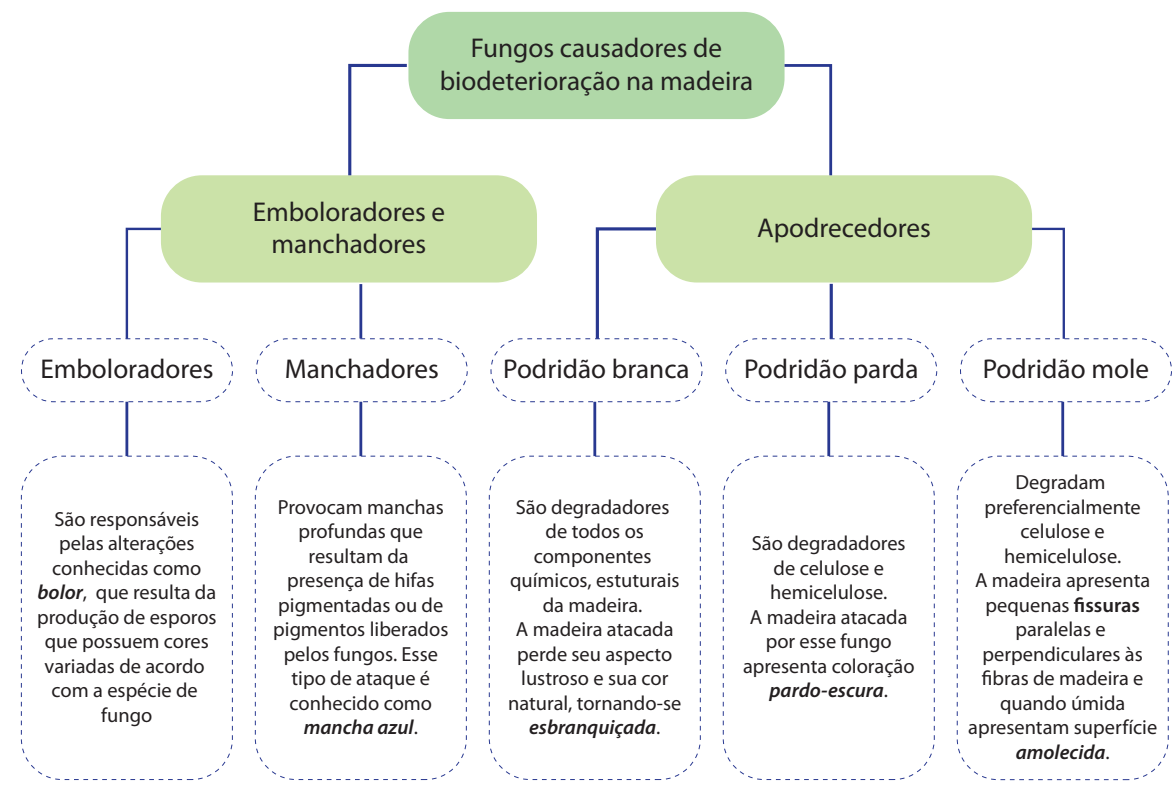

Figura 4. Fungos deterioradores da madeira. Adaptado de IPT (2001).

Os fungos que causam descoloração na madeira armazenada e em serviço são geralmente definidos como fungos manchadores, já os fungos emboloradores, que crescem na superfície da madeira, possuem hifas que podem penetrar profundamente no alburno sem afetar a coloração da madeira, (OLIVEIRA et al., 1986). Ambos os fungos, os emboloradores e os manchadores, conferem prejuízo à qualidade estética dos produtos à base de madeira, devido à descoloração. Existem várias metodologias que são amplamente usadas para determinar a resistência natural ao apodrecimento e colonização de fungos da madeira.

Fungos causadores de podridáo branca ocasionam a perda progressiva de massa e das propriedades de resistência em decorrência do contínuo consumo de celulose, hemicelulose e lignina. No caso de fungos causadores de podridão parda, a madeira, uma vez seca, apresenta o aspecto de estar levemente queimada, adquirindo coloração parda, a madeira sofre colapso com facilidade e desenvolve inúmeras fissuras paralelas e perpendiculares (MORESCHI, 1995). Os fungos de podridáo parda são mais eficientes na decomposição da celulose e hemicelulose. São incapazes de metabolizar anéis aromáticos ou seus produtos alifáticos. Ao atacar polissacarídeos associados à lignina, removem o grupo de $\mathrm{CH}_{3}$ e as cadeias laterais $\mathrm{R}-\mathrm{O}-\mathrm{CH}_{3}$ da lignina, deixando os fenóis 
que, ao se oxidarem, tornam-se marrons ou pardos. Como é o caso dos fungos: Poria coeus, Lenzites trabea e Gloeophyllum trabeum (MOREIRA, SIQUEIRA, 2006). Os fungos de podridáo mole são amplamente encontrados na natureza causando deterioraçáo na madeira exposta a ambientes aquáticos e terrestres. São particularmente ativos em condiçôes de alta umidade e pouco oxigênio, que inibe a atividade dos fungos causadores da podridáo branca e da podridão parda (IPT, 2001; DANIEL et al., 1998).

\subsection{Métodos de Avaliação de Durabilidade}

Com o objetivo de prever a vida útil de um material ou componente construtivo, de acordo com o tipo de aplicação, devem ser definidos, previamente, as principais propriedades físico-mecânicas e os mecanismos de degradaçáo do material submetido a ensaios de envelhecimento natural ou acelerado, assim como as metodologias usadas para a sua determinação. Os métodos de envelhecimento para avaliar a durabilidade de painéis derivados de madeira incluem testes de longo prazo e de curto prazo. Testes de longo prazo (envelhecimento natural) são os ensaios de exposiçáo ao ar livre, para avaliar a influência das intempéries (HAYASHI et al., 2002). No entanto, as respostas do envelhecimento natural são lentas. Desse modo, buscase aplicar ensaios de envelhecimento acelerado (curto prazo) que simulem parcialmente os de envelhecimento natural (Figura 5). Portanto, o uso dos ensaios de envelhecimento acelerado, em laboratório, tem como objetivo fornecer dados, em curto prazo, sobre a durabilidade, bem como a respeito dos fatores de degradação. Normalmente, são aplicados em paralelo aos ensaios de envelhecimento natural e os de envelhecimento acelerado para avaliar o material, pois os dados obtidos em ambos são complementares.

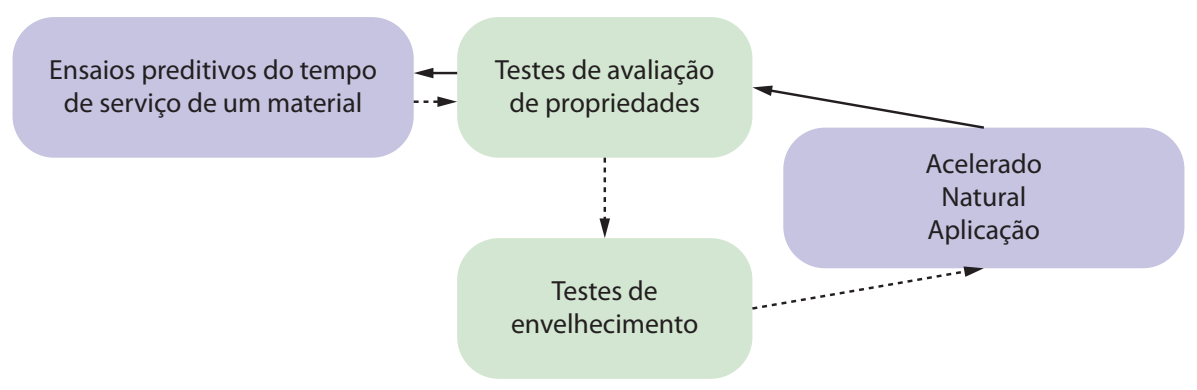

Figura 5. Ensaios de durabilidade de um material. 
Segundo Crewdson (2009), o uso de algumas condiçóes exageradas nos ensaios de envelhecimento pode levar a conclusóes erradas, e muita confiança apenas em testes acelerados pode ser potencialmente enganador. Ensaios de durabilidade ao ar livre (intemperismo) devem ser utilizados para avaliar a eficiência dos ensaios acelerados. Com um procedimento de teste de envelhecimento acelerado correto, busca-se correlacionar os dados com aqueles obtidos no ensaio de envelhecimento ao ar livre. Desse modo, pode-se fazer um desenho experimental do ensaio acelerado que gere dados próximos aos ensaios de envelhecimento natural, sendo, para isso, necessário o uso de avaliaçóes apropriadas, por meio de materiais de controle e pelo uso de análise estatística de confiança.

\subsubsection{Envelhecimento Natural}

A durabilidade de painéis à base de madeira ou de resíduos agroindustriais é um aspecto importante quando se planeja seu uso na construção civil, visando a determinar o desempenho ao longo prazo. No entanto, a durabilidade dos materiais em condições de exposição varia com o local de aplicação. Essa situação se apresenta, por exemplo, quando se deseja aplicar normas ou resultados obtidos em países de clima temperado, em condiçóes climáticas tâo diferentes quanto a brasileira. Exposiçôes do material em diferentes locais, assim como durante vários anos, pode aumentar a confiabilidade dos resultados sobre a durabilidade. Considerando a estrutura peculiar e os mecanismos de degradação dos painéis particulados, é necessário proceder a uma exposição ao ar livre e avaliar com mais precisão sua durabilidade (SEKINO, 2003).

A bancada para expor corpos-de-prova ao envelhecimento natural depende do ângulo de exposição relativo à horizontal, como mostra a Figura 6. Esse ângulo pode variar dependendo das condiçôes de uso final do material. $\mathrm{O}$ ângulo de $0^{\circ}$ é pouco utilizado em painéis em estruturas planas, devido à água não escorrer. $\mathrm{O}$ típico ângulo na mesa de exposição usado em produtos para automóveis é de $5^{\circ}$. Ângulos de $25^{\circ}$ ou $34^{\circ}$ são usados para maximizar a radiação solar. $\mathrm{O}$ ângulo de $45^{\circ}$ é usado em materiais que não têm o uso final definido e o ângulo de $90^{\circ}$ é usado para avaliar materiais que serão submetidos à baixa temperatura, à baixa radiação solar e à baixa umidade relativa. 
(b)
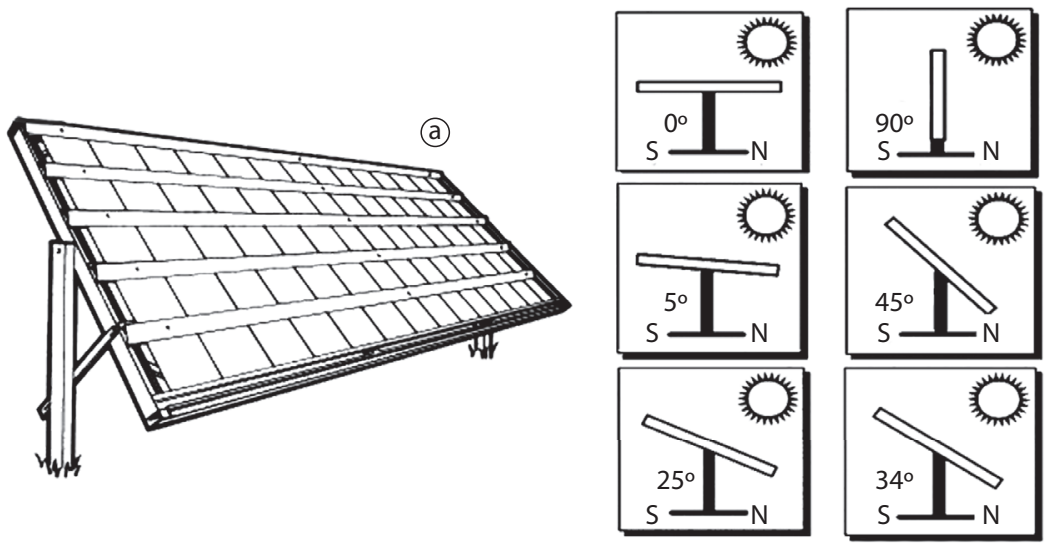

Figura 6. Envelhecimento natural a) bancada b) Ângulo de exposição de materiais ao ar livre (hemisfério sul). Fonte Q-lab (2011).

A utilização de campos de exposição natural ou de envelhecimento natural são especialmente úteis para identificar: a) perda de resistência mecânica e deterioração física do material; b) variação dimensional do material causada pela temperatura e pela umidade; c) estudos de temperatura máxima de serviços; d) Mudança de cor, desbotamento e perda de brilho; e) Rachaduras, deformação e envelhecimento pelo calor; f) Mecanismos de biodegradação.

\subsubsection{Envelhecimento Acelerado}

Os ensaios de envelhecimento são aqueles nos quais os materiais ou componentes construtivos são submetidos ou expostos a fatores de degradação específicos que podem ocorrer no envelhecimento natural, como a radiação ultravioleta, a umidade e a temperatura, com uma intensidade acima da expectativa de serviço. Normalmente, no envelhecimento acelerado, o material é exposto à sequência de fatores de degradação em condiçóes controladas até completar um ciclo. No entanto, o número de ciclos nos ensaios é diferente das condições reais de degradação do material (SEKINO, 2003; GARZON et al., 2012). Entretanto, o uso de um teste de envelhecimento acelerado ajuda a estimar a durabilidade de um material ou componente por meio da comparação ao avaliar, por exemplo, as propriedades físico-mecânicas antes e após a realização do teste (KARLSSON, 1996). A Tabela 2 lista as 
metodologias de envelhecimento acelerado usadas para avaliar a durabilidade de painéis particulados em laboratório.

Tabela 2. Metodologias de envelhecimento acelerado em laboratório

\begin{tabular}{|c|c|c|c|c|}
\hline Método & Tipo de Exposição & $\begin{array}{l}\text { Temperatura } \\
\left({ }^{\circ} \mathrm{C}\right)\end{array}$ & $\begin{array}{l}\text { Pressão } \\
\text { (kPa) }\end{array}$ & Tempo (h) \\
\hline \multirow[t]{3}{*}{ Cycle JIS-B } & Imersão em água & 100 & NC & 2 \\
\hline & Imersão em água & 20 & NC & 1 \\
\hline & Ar quente e seco & 60 & NC & 21 \\
\hline Cyclic APA & Imersão em água & 66 & NC & 8 \\
\hline \multicolumn{5}{|l|}{ D-1 } \\
\hline & Ar quente e seco & 82 & NC & 14,5 \\
\hline & Acondicionamento & $\mathrm{NC}$ & NC & 1,5 \\
\hline \multirow[t]{4}{*}{ V313 } & Imersão em água & 20 & NC & 72 \\
\hline & Congelamento & $(-12)$ & NC & 24 \\
\hline & Ar quente e seco & 70 & NC & 72 \\
\hline & Acondicionamento & NC & NC & 4 \\
\hline \multirow{6}{*}{$\begin{array}{l}\text { ASTM D } 1037 \\
\text { ( } 6 \text { ciclos ) }\end{array}$} & Imersão em água & 49 & NC & 1 \\
\hline & Vapor & 93 & NC & 3 \\
\hline & Congelamento & $(-12)$ & NC & 20 \\
\hline & Ar quente e seco & 99 & NC & 3 \\
\hline & Vapor & 93 & NC & 3 \\
\hline & Ar quente e seco & 99 & NC & 18 \\
\hline \multirow[t]{3}{*}{ VPSD } & Vácuo & NC & NC & 0,5 \\
\hline & Imersão com pressão & NC & 290 & 1 \\
\hline & Ar quente e seco & 60 & $\mathrm{NC}$ & 22 \\
\hline EN 321-2001 & Imersão em água & 20 & NC & 72 \\
\hline \multirow[t]{3}{*}{ (3 ciclos) } & Congelamento & -20 & & 24 \\
\hline & Ar quente e seco & 70 & & 72 \\
\hline & $\begin{array}{l}\text { Acondiconamento } \\
\text { (50\%UR) }\end{array}$ & 25 & & 72 \\
\hline
\end{tabular}

NC: Nada consta ; ASTM American Society For Testing And Materials; APA Engineered Wood Association; V313 European Standard ; JIS Japanese Industrial Standards ; VPSD: Vacuum, Pressure,; Soaking and Drying. Ensaio para Melamine Faced Chipboard (MFC) ; European Committee for Standardization. European Standard. DINEN 321. Fonte: Própria autoria. 


\subsubsection{Biodeterioração por Ataque de Fungos}

A quantificação da degradação gerada pelos fatores biológicos é necessária para estimar as medidas de proteção e preservação requeridas pelos materiais. Segundo Schefer (1971), a biodeterioração biológica gerada por fungos está relacionada diretamente com as condiçôes de precipitação e temperatura. Em lugares com climas mais úmidos e quentes, os materiais de madeira e derivados são mais suscetíveis à proliferação e ao ataque de fungos do que aqueles locais com climas mais frescos e secos. Os fungos podem colonizar em qualquer substrato (material) que provê quantidade suficiente de nutrientes e água (TANACA et al., 2011).

Segundo Monteiro e Freitas (1997), dois materiais podem apresentar propriedades mecânicas semelhantes, porém, apresentar resistência natural diferente, uma vez sujeitos a ataques biológicos. Por isso, para o possível uso de materiais de madeira e seus derivados, no caso desta pesquisa, painéis particulados à base de resíduos agroindustriais, faz-se necessário avaliar sua suscetibilidade aos fatores biológicos (fungos) para determinar sua durabilidade natural.

Algumas das metodologias amplamente usadas para determinar a resistência natural ao apodrecimento e à colonização de fungos da madeira e dos elementos de preservação e conservação são apresentadas na Tabela 3. Essas metodologias determinam a perda de massa dos corpos-de-prova submetidos ao ensaio de biodeterioração, como medida indireta de sua resistência natural ao apodrecimento, indicando uma estimativa de resistência relativa dos materiais avaliados ao ataque de fungos que causam podridão branca e/ ou parda. Para os fungos emboloradores, são analisadas as porcentagens de colonização do fungo no corpo. Os métodos de biodegradação acelerados permitem, em um tempo relativamente curto, obter resultados e orientar a escolha do uso final do produto comparado com o tempo que levaria para avaliar em um processo de biodeterioração natural de um material orgânico em condiçôes reais de uso. 
Tabela 3. Normas de avaliação da biodeterioração biológica

\begin{tabular}{|c|c|c|c|}
\hline Fungo avaliado & Norma & Descrição & $\begin{array}{l}\text { Tempo de } \\
\text { ensaio }\end{array}$ \\
\hline $\begin{array}{l}\text { Fungos } \\
\text { Apodrecedores }\end{array}$ & $\begin{array}{l}\text { ASTM D } \\
\text { 2017/05 } \\
\text { Método } \\
\text { Acelerado de } \\
\text { Laboratório } \\
\text { resistência } \\
\text { natural de } \\
\text { madeiras }\end{array}$ & $\begin{array}{l}\text { Chamado "SOIL BLOCK" por usar } \\
\text { como meio de cultura o solo. Avalia a } \\
\text { resistência à deterioração natural da } \\
\text { madeira ou resistência de materiais } \\
\text { orgânicos à fungos apodrecedores. Os } \\
\text { fungos especificados pela norma são: } \\
\text { Gloeophyllum trabeum, Postia Placenta } \\
\text { e Tramestes Versicolor. A resistência } \\
\text { do material é avaliada por meio da } \\
\text { porcentagem da perda de massa. }\end{array}$ & $\begin{array}{l}16 \\
\text { semanas }\end{array}$ \\
\hline & $\begin{array}{l}\text { EN 113/ } 1996 \\
\text { Comite Europeen } \\
\text { de Normalization } \\
\text { /CEN } \\
\text { Método de } \\
\text { ensaio para } \\
\text { determinar } \\
\text { a eficácia } \\
\text { protetora contra } \\
\text { destruidores da } \\
\text { madeira. }\end{array}$ & $\begin{array}{l}\text { Nesse ensaio os corpos-de-prova } \\
\text { são tratados com conservante e, em } \\
\text { seguida, são expostos ao ataque de } \\
\text { fungos sobre um meio "AGAR BLOCK". } \\
\text { Após um período de exposição, são } \\
\text { calculadas as perdas de massa das } \\
\text { amostras. Essa perda de massa é a } \\
\text { medida de eficácia. Quanto menor } \\
\text { for a perda de massa, mais eficaz é o } \\
\text { conservante. }\end{array}$ & $\begin{array}{l}16 \text { de } \\
\text { semanas }\end{array}$ \\
\hline $\begin{array}{l}\text { Fungos } \\
\text { emboloradores }\end{array}$ & $\begin{array}{l}\text { ASTM D 3273- } \\
\mathbf{2 0 1 2} \\
\text { Método para a } \\
\text { resistência ao } \\
\text { crescimento } \\
\text { de fungos } \\
\text { emboladores } \\
\text { sobre a } \\
\text { superfície dos } \\
\text { revestimentos } \\
\text { interiores de } \\
\text { uma câmara } \\
\text { ambiental. }\end{array}$ & $\begin{array}{l}\text { É um método utilizado para simular } \\
\text { um ambiente severo de exposição, } \\
\text { principalmente a alta umidade e } \\
\text { temperatura. Esse método determina } \\
\text { a resistência do material e permite } \\
\text { avaliar se o(s) produto(s) usados como } \\
\text { proteção são ou não apropriados } \\
\text { e formulados para altas umidades } \\
\text { e temperaturas, ao crescimento } \\
\text { de fungos emboloradores. Após } \\
\text { a conclusão do teste, a amostra } \\
\text { é classificada de } 0 \text { a } 10 \text {, sendo } 0 \\
\text { equivalente à ausência de crescimento } \\
\text { e } 10 \text { ao crescimento intenso de fungos }\end{array}$ & 28 dias \\
\hline
\end{tabular}

Fonte: Própria autoria. 
Tabela 3. Continuação.

\begin{tabular}{|c|c|c|c|}
\hline Fungo avaliado & Norma & Descrição & $\begin{array}{l}\text { Tempo de } \\
\text { ensaio }\end{array}$ \\
\hline \multirow[t]{4}{*}{$\begin{array}{l}\text { Fungos } \\
\text { emboloradores }\end{array}$} & $\begin{array}{l}\text { ASTM D-5590- } \\
\mathbf{2 0 1 0} \\
\text { Resistência dos } \\
\text { filmes de tintas } \\
\text { e revestimentos } \\
\text { relacionados com } \\
\text { a desfiguração } \\
\text { fúngica em } \\
\text { quatro semanas. }\end{array}$ & $\begin{array}{l}\text { Após a conclusão do teste, a amostra } \\
\text { é classificada de } 0 \text { a } 4 \text {, onde } 0 \text { equivale } \\
\text { a ausência de crescimento e } 4 \text { ao } \\
\text { crescimento intenso. Alguns dos } \\
\text { fungos especificados pela norma são: } \\
\text { Aspergillus Níger e Penicillium Citrinum. }\end{array}$ & 16 días \\
\hline & $\begin{array}{l}\text { ASTM G21 - } 15 \\
\text { Resistência } \\
\text { dos materiais } \\
\text { sintéticos } \\
\text { poliméricos } \\
\text { ao ataque de } \\
\text { fungos }\end{array}$ & $\begin{array}{l}\text { Nesse metodo é realizada a } \\
\text { inoculação das amostras com fungos } \\
\text { emboloradores. A classificação varia de } \\
0 \text { a } 4 \text {, sendo } 0 \text { equivalente à ausência de } \\
\text { crescimento e } 4 \text { ao crescimento intenso. } \\
\text { Alguns dos fungos especificados pela } \\
\text { norma são: Aspergillus brasiliensis, } \\
\text { Penicillium funiculosum, Chaetomium } \\
\text { globosum Trichoderma virens, } \\
\text { Aureobasidium pullulans. }\end{array}$ & 28 dias \\
\hline & $\begin{array}{l}\text { ASTM1413 - } 08 \\
\text { Resistência de } \\
\text { prevervativos } \\
\text { de madeira } \\
\text { ao ataque de } \\
\text { fungos }\end{array}$ & $\begin{array}{l}\text { Método de ensaio que abrange a } \\
\text { determinação da quantidade mínima } \\
\text { de preservativos de modo a evitar a } \\
\text { deterioração das espécies selecionadas } \\
\text { de madeira por fungos selecionados } \\
\text { em condições laboratoriais ideais. } \\
\text { Alguns dos fungos especificados } \\
\text { pela norma são: Neolentinus lepideus, } \\
\text { Gloeophyllum trabeum ,Postia placenta, } \\
\text { Trametes versicolor. }\end{array}$ & $\begin{array}{l}12 \\
\text { semanas }\end{array}$ \\
\hline & $\begin{array}{l}\text { ABNT NBR } \\
\text { 14941:2011 }\end{array}$ & $\begin{array}{l}\text { Método para avaliação do } \\
\text { desempenho de tintas para } \\
\text { edificações não industriais -Método } \\
\text { para determinação da resistência de } \\
\text { películas não lixiviadas, de produtos } \\
\text { classificados conforme ABNT NBR } \\
11702 \text {, ao crescimento do fungo } \\
\text { Aspegillus niger, em placa de Petri. }\end{array}$ & 14 dias \\
\hline
\end{tabular}

Fonte: Própria autoria. 


\section{Fabricação de Painéis Particulados}

\subsection{Fabricação de Painéis de Partículas de Bagaço de Cana-de-açúcar e Resina Poliuretana à Base de Óleo de Mamona (BCP)}

A fabricação dos painéis de partículas de bagaço de cana-de-açúcar a partir do emprego de resíduos da agroindústria e resina poliuretana bicomponente à base de óleo de mamona foi executada em condiçóes controladas de laboratório, seguindo as recomendaçóes estabelecidas por Maloney (1996). As características do painel e do processo de fabricação são elencadas na Tabela 4. O desempenho físico e mecânico dos painéis particulados foi analisado com base nas prescriçóes dos documentos normativos ABNT NBR 14810 (2006) e ANSI A208.1 (1999).

Tabela 4. Características do painel de partículas de bagaço de cana de açúcar.

\begin{tabular}{ll}
\hline Característica & Descrição \\
\hline Dimensões & $40 \times 40 \mathrm{~cm}$ \\
\hline Espessura & $12 \mathrm{~mm}$ \\
\hline Densidade & $800 \mathrm{~kg} / \mathrm{m}^{3}$ \\
\hline Tipo de painel & Aglomerado convencional \\
\hline Distribuição de partículas no painel & Homogênea \\
\hline Método de prensagem & Convencional \\
\hline
\end{tabular}

O processo iniciou-se com a coleta do bagaço de cana-de-açúcar em duas usinas sucroalcooleiras da regiáo de Pirassununga - SP, Brasil. O material foi peneirado em malha de $2 \mathrm{~mm}$ para retirar as partículas mais finas. Posteriormente, foi picado em um moinho de facas com peneira de $8 \mathrm{~mm}$ e seco em estufa $\left(60^{\circ} \mathrm{C}\right)$ até atingir a umidade de equilíbrio de $12 \%$. Como aglomerante das partículas de bagaço de cana-de-açúcar, foi utilizada resina poliuretana bicomponente à base de óleo de mamona, sendo um dos componentes o poliol derivado do óleo vegetal, e o outro o isocianato polifuncional, em uma proporção de 2 partes de catalisador para 1 parte de poliol, sendo $15 \%$ da massa. A resina e as partículas foram misturadas em um batedor planetário durante $3 \mathrm{~min}$. Posteriormente, as partículas foram inseridas em um molde formador de painel $(50 \times 50 \mathrm{~cm})$ e inserida em prensa 
termo-hidráulica a $100^{\circ} \mathrm{C}$ e $5 \mathrm{MPa}$ de pressão, por $10 \mathrm{~min}$. $\mathrm{O}$ painel foi esquadrejado, retirando-se as bordas para seu acabamento final (Figura 7).
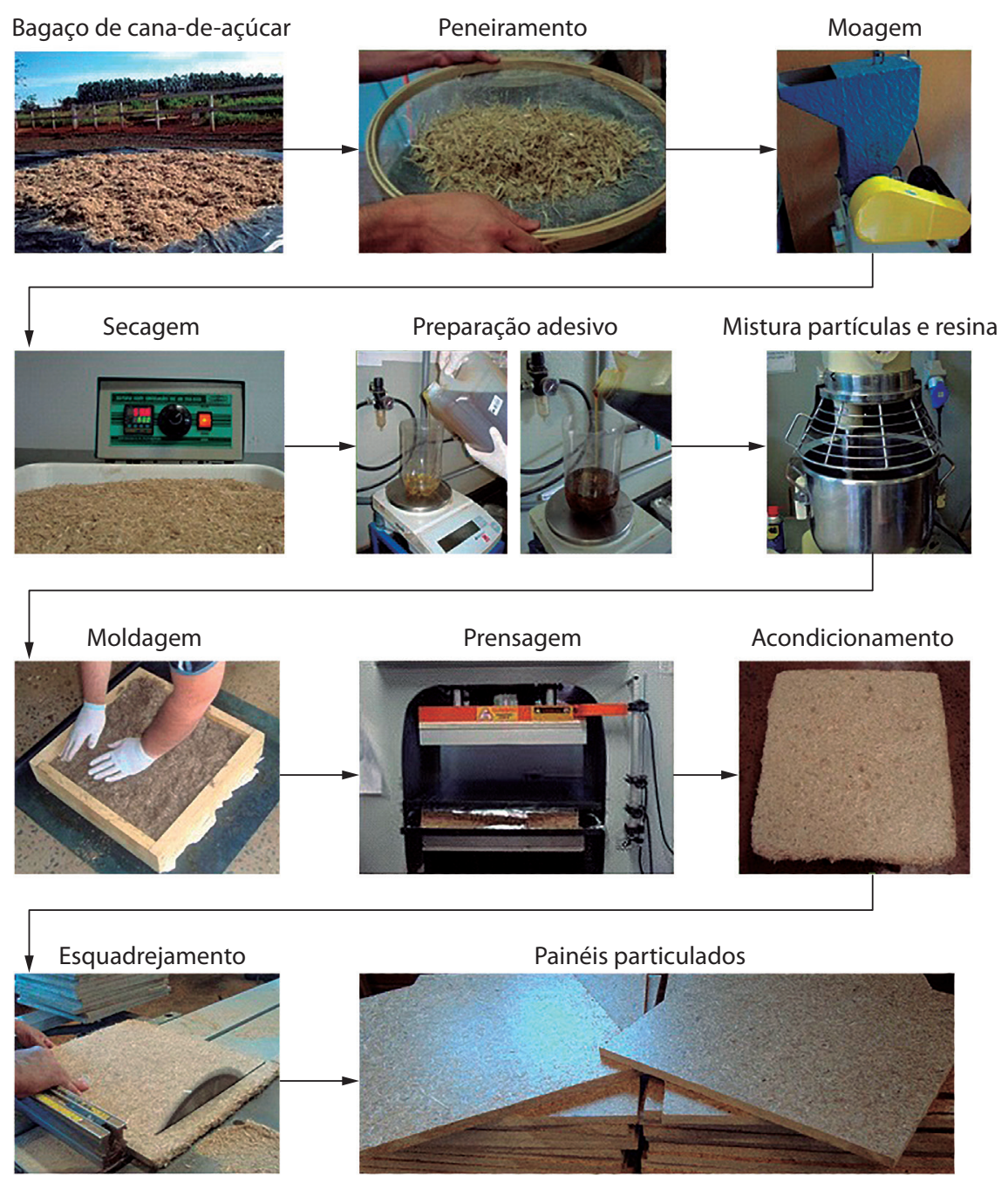

Figura 7. Fluxograma ilustrativo do processo de fabricação dos painéis particulados com bagaço de cana-de-açúcar

\subsection{Painel de Madeira Comercial (MDP)}

Foi adquirido um painel multicamada comercial $(15 \times 1830 \times 2750 \mathrm{~mm})$, denominado MDP (Medium Density Particleboard), com $15 \mathrm{~mm}$ de espessura, 
sendo confeccionado com partículas de Eucaliptus sp e com resina de uréiaformaldeído.

\subsection{Tratamentos Lateral e Superficial dos Corpos de Prova}

Os corpos-de-prova de $27 \times 5 \mathrm{~cm}$ de BCP e MDP foram submetidos a um tratamento lateral para a selagem das bordas, com objetivo de diminuir a entrada de água por meio dessa superfície, durante os ensaios de envelhecimento natural e acelerado (Figura 8).
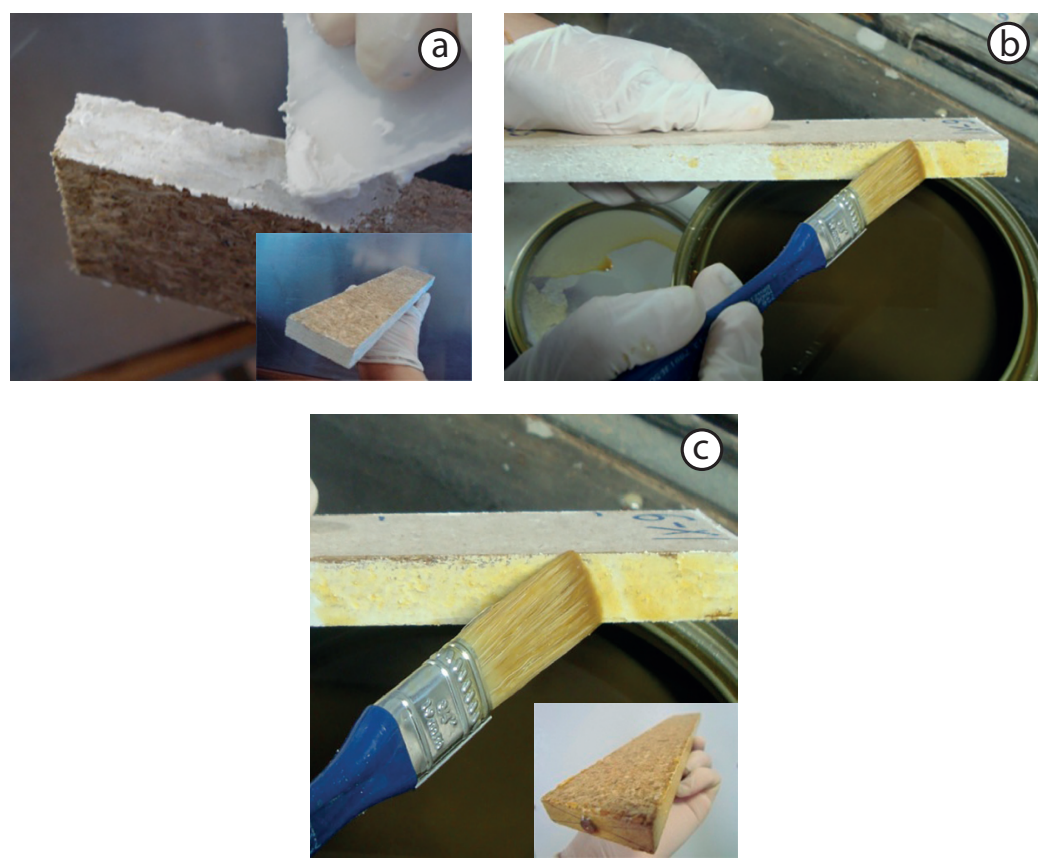

Figura 8. (a) Selagem de bordas com massa acrílica, (b) aplicação de selante nas bordas e (c) aplicação de verniz marítimo.

Para o tratamento superficial, a metade dos corpos-de-prova extraídos dos painéis, tanto os elaborados com bagaço de cana-de-açúcar quanto o comercial, foram tratados superficialmente com resina poliuretana à base de óleo de mamona, usado como revestimento externo. Foi misturada uma proporção de 1 parte de poliol para 1 parte do catalisador. $O$ tratamento teve como objetivo avaliar a proteção do material contra os agentes (água, umidade e temperatura) e seus mecanismos de degradação durante a avaliação da durabilidade, feita por meio dos ensaios de envelhecimento. De igual maneira, 
pretendeu-se verificar o efeito de proteçáo da resina de óleo de mamona como revestimento superficial. A resina foi aplicada utilizando-se uma pistola de ar comprimido. A Figura 9 indica o procedimento adotado.
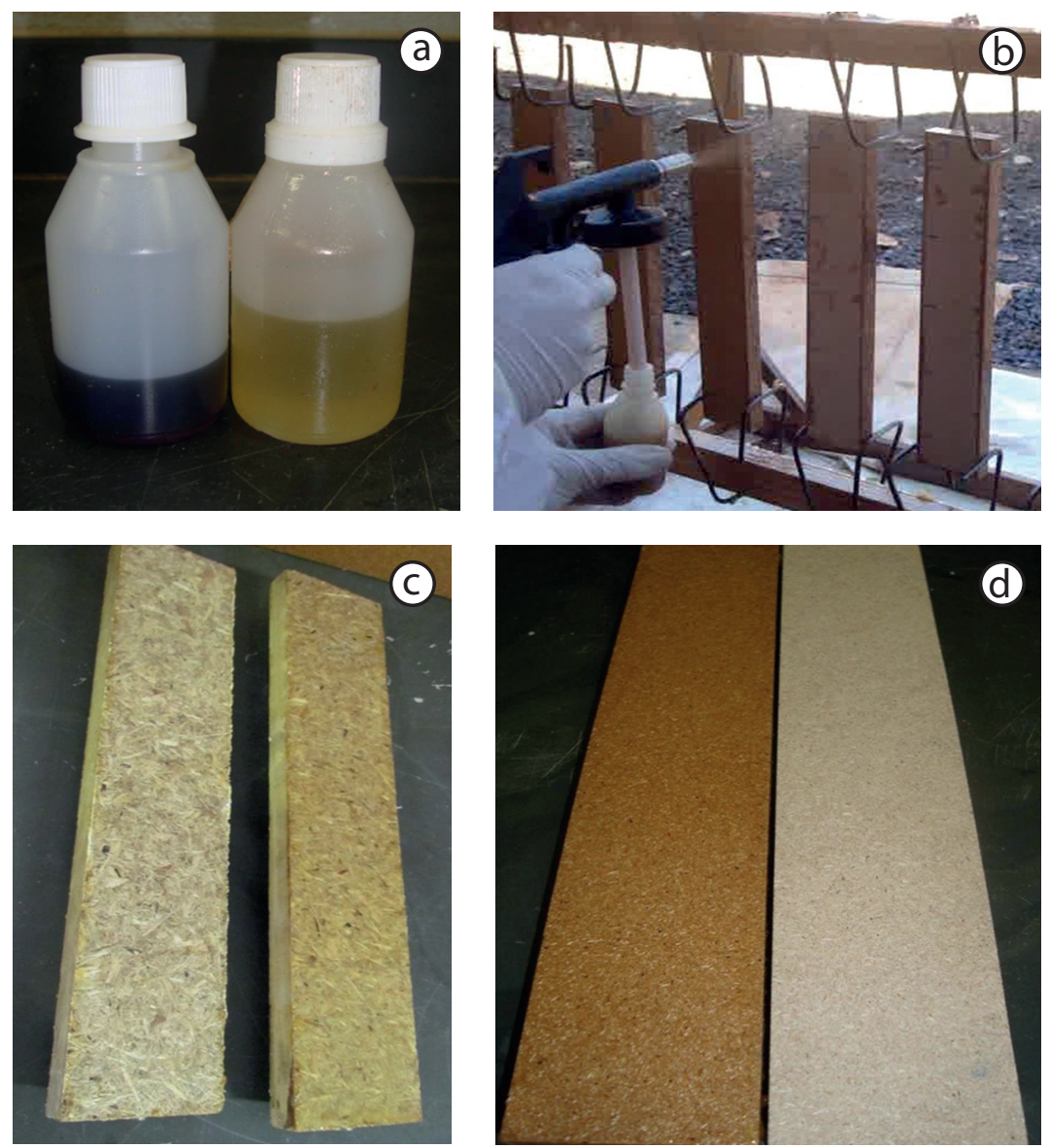

Figura 9. a) Resina poliuretana à base de óleo de mamona: catalisador (esquerda) e poliol (direita). b) Aplicação de resina com pistola de ar comprimido. c) Corposde-prova BCP. d) Corpos-de-prova MDP.

\section{Envelhecimento e Caracterização de Painéis Particulados}

Foram realizados ensaios de envelhecimento acelerado baseados na norma APA D1 e os agentes de deterioração foram analisados em duas condiçôes: C1 - Umidade Relativa e C2 - Temperatura. 


\subsection{Ensaios por Ciclos de Envelhecimento Acelerado APA D1:1999}

Os corpos-de-prova foram submetidos a seis ciclos de envelhecimento acelerado, tendo como variáveis a umidade relativa e a temperatura. Os equipamentos utilizados foram: (i) câmara climática, (ii) banho térmico com circulação de água, e (iii) estufa com circulação de ar (Figura 10). Antes do início dos testes, os corpos-de-prova foram armazenados por $48 \pm 0,5 \mathrm{~h}$ à temperatura de $20 \pm 5^{\circ} \mathrm{C}$ e umidade relativa de $65 \pm 2 \%$. A Tabela 5 apresenta as condiçóes de exposição do ensaio de envelhecimento.

Tabela 5. Condições de exposição no ensaio APA D1:1994.

\begin{tabular}{llll}
\hline Método & Etapa & Temperatura $\left({ }^{\circ} \mathbf{C}\right)$ & Tempo $(\mathbf{h})$ \\
\hline APA D & Imersão água & 66 & 8 \\
\cline { 2 - 4 } $\mathbf{1}$ Ciclo & Ar quente e seco & 82 & 14,5 \\
\cline { 2 - 4 } & Acondicionamento & 1,5 \\
\hline Total & & & 24 \\
\hline
\end{tabular}
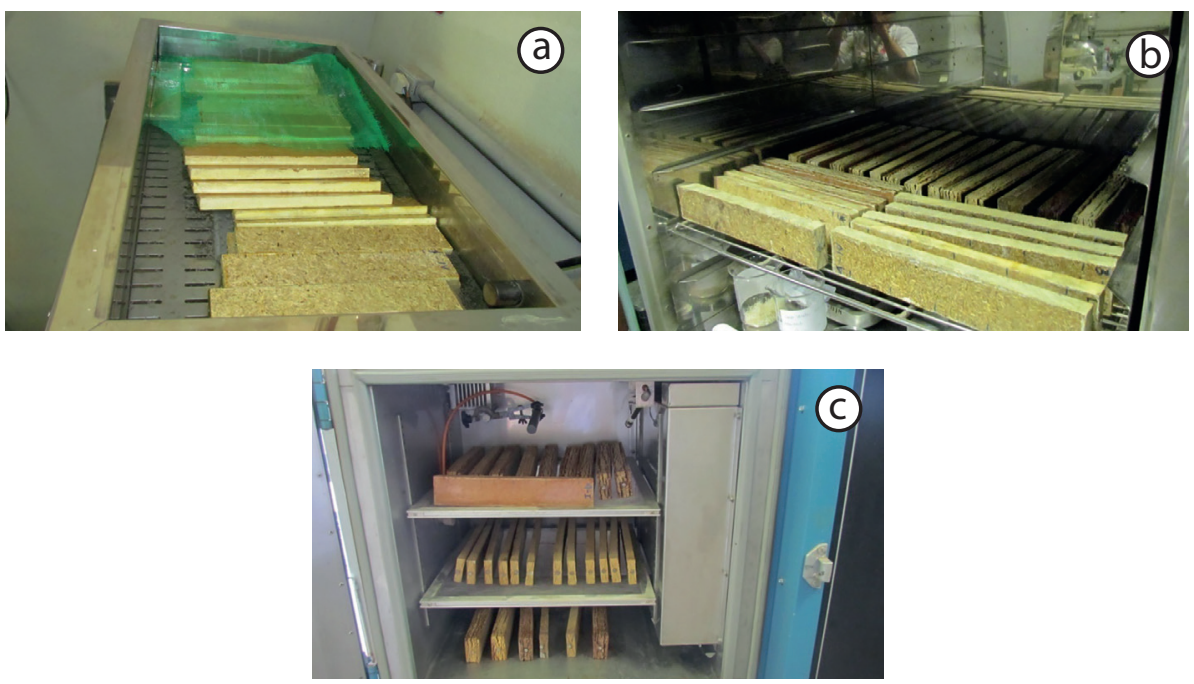

Figura 10. Ełapas do ensaio APA D-1: a) Imersão, b) Ar quente e seco e c) Acondicionamento. 


\subsection{Exposição a Agentes Isolados de Envelhecimento Acelerado}

A fim de determinar o efeito dos agentes de envelhecimento acelerado, os corpos-de-prova foram submetidos a duas exposiçóes, conforme detalhado na Tabela 6.

Tabela 6. Condições de exposição aos agentes de degradação isolados.

\begin{tabular}{|c|c|c|c|c|c|}
\hline Condição 1 (C1) & & & Condição 2 (C2) & & \\
\hline $\begin{array}{l}\text { Agente de } \\
\text { degradação }\end{array}$ & Valor & $\begin{array}{l}\text { Tempo } \\
\text { (h) }\end{array}$ & $\begin{array}{l}\text { Agente de } \\
\text { degradação }\end{array}$ & Valor & $\begin{array}{l}\text { Tempo } \\
\text { (h) }\end{array}$ \\
\hline Umidade relativa (\%) & 93 & 8 & Temperatura $\left({ }^{\circ} \mathrm{C}\right)$ & 82 & 14,5 \\
\hline \multirow[t]{2}{*}{ Acondicionamento } & $U R=65 \%$ & \multirow[t]{2}{*}{1,5} & \multirow[t]{2}{*}{ Acondicionamento } & $U R=65 \%$ & \multirow[t]{2}{*}{1,5} \\
\hline & $\mathrm{T}=20^{\circ} \mathrm{C}$ & & & $\mathrm{T}=20^{\circ} \mathrm{C}$ & \\
\hline
\end{tabular}

\subsection{Envelhecimento Natural}

$\mathrm{O}$ ensaio de envelhecimento natural seguiu os procedimentos do documento normativo ASTM D 1435:1994 - Standard Practice for Outdoor Weathering of Plastics. Esse ensaio foi realizado na FZEA/USP, em uma bancada metálica inclinada a $31^{\circ}$ e voltada para a face norte (latitude $21^{\circ}$ $59^{\prime}$ S), em Pirassununga, Brasil. Os grupos de corpos-de-prova para o ensaio de envelhecimento foram colocados no dia 25 de junho de 2012 e expostos às intempéries durante 3 e 6 meses. Radiação solar, precipitação total, temperatura e umidade relativa foram analisadas para o período de exposiçáo total de acordo com os dados disponibilizados pela estação meteorológica da Universidade de São Paulo, localizada no campo de exposição (Figura 11). Antes da avaliação das propriedades físico-mecânicas, os corpos-de-prova foram acondicionados à umidade relativa de $50+20 \%$ e à temperatura de $23+5^{\circ} \mathrm{C}$. 


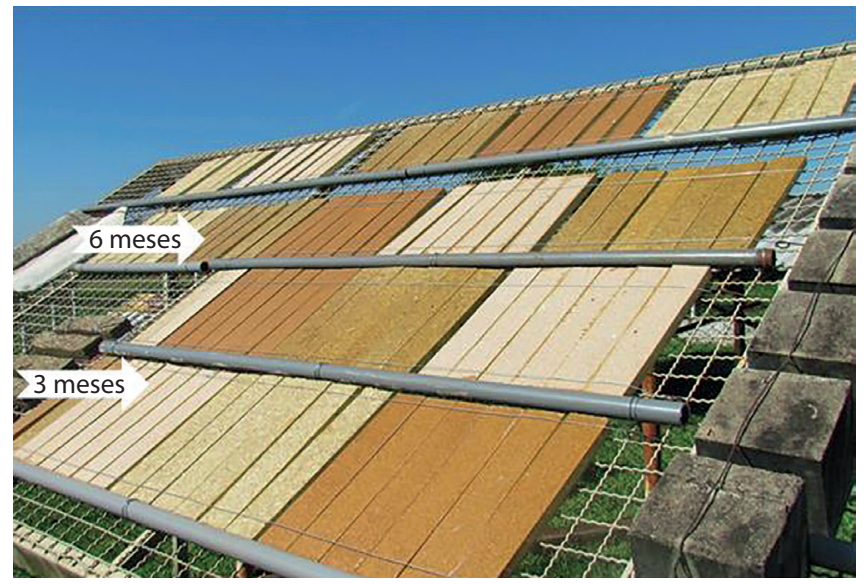

Figura 11. Bancada de exposição para envelhecimento natural Campus USP/ Pirassununga.

\subsection{Caracterização Físico-mecânica}

Após os ensaios de envelhecimento, foi realizada a avaliação das propriedades físico-mecânica dos painéis particulados produzidos em laboratório (BCP) e em escala industrial (MDP). As dimensōes dos corpos-de-prova foram $270 \times 50 \mathrm{~mm}$ para determinar as seguintes propriedades: Modulo de Ruptura (MOR), Módulo de Elasticidade (MOE) e Inchamento em Espessura (IE). Corpos-de-prova com 50 x $50 \mathrm{~mm}$ foram utilizados para determinar a adesão interna (AI) e a densidade aparente (DA). Após os ensaios de envelhecimento, os corpos-de-prova foram acondicionados a uma temperatura de $\left(20{ }^{\circ} \mathrm{C}\right.$ e $65 \%$ de umidade relativa), por uma semana. O equipamento utilizado os ensaios foi a máquina universal de ensaios mecânicos, modelo DL30000, marca EMIC, do Laboratório de Construçóes e Ambiência, do Departamento de Engenharia de Biossistemas, da Faculdade de Zootecnia e Engenharia de Alimentos, da Universidade de Sáo Paulo, Campus de Pirassununga, seguindo as recomendaçôes da NBR 14810:2006. Os valores obtidos foram comparados com aqueles estabelecidos nos ensaios pelas normas NBR 14810:2006 e ANSI A208.1 (1999).

\subsection{Análise Estatística dos Resultados Experimentais}

A possível heterogeneidade de variâncias nas diferentes condições de envelhecimento foi testada utilizando os Critérios de Informação de Akaike (AIC) e Bayesiano ou de Schwarz (BIC) utilizando o proc glimmix do SAS $^{(\oplus)}$, 
em ajustes feitos com duas diferentes estruturas de covariâncias (VC: variance components e VC com group = Tempo) para condição de envelhecimento. Segundo esses critérios, o melhor modelo é aquele que apresenta o menor AIC (ou menor BIC).

\section{Análise dos Materiais Expostos aos Ensaios de Envelhecimento Acelerado}

\subsection{Propriedades Físicas}

Os valores de densidade aparente, após as diferentes condiçóes de envelhecimento acelerado, apresentaram interação tripla ( $\mathrm{p}$-valor $<0,0434$ ) entre os tipos de materiais (BCP, MDP), o revestimento superficial (Com e Sem), e as condiçôes de envelhecimento acelerado (APA D1, C1 e C2). A Tabela 7 apresenta os resultados obtidos para a densidade aparente após o ensaio de envelhecimento acelerado (APA D1) e as duas condições de degradação C1 e C2. Ao analisar as condiçóes em cada material nos diferentes tratamentos de revestimento superficial, pode-se observar a diferença estática para todas as situaçôes. A densidade aparente para os corpos de prova submetidos ao ensaio de envelhecimento acelerado (APA D1) apresentou, no caso dos compósitos com bagaço de cana-de-açúcar e resina poliuretana de mamona, um comportamento similar ao daqueles que foram submetidos a altas temperaturas.

Tabela 7. Valores médios de densidade aparente após ensaios de envelhecimento acelerado.

\begin{tabular}{|c|c|c|c|c|c|c|}
\hline \multirow[t]{3}{*}{ Material } & \multirow{3}{*}{$\begin{array}{l}\text { Revestimento } \\
\text { Superficial }\end{array}$} & \multicolumn{5}{|c|}{ Condição de envelhecimento acelerado } \\
\hline & & 0 Ciclos & APA D1 & C1 & $\mathbf{C 2}$ & P-valor \\
\hline & & \multicolumn{5}{|c|}{ Densidade Aparente $\left(\mathrm{kg} / \mathrm{m}^{3}\right)$} \\
\hline BCP & COM & $859 \quad \mathrm{~A}, \mathrm{a}$ & 791 & 841 & $A B, a$ & 0,0005 \\
\hline BCP & SEM & $849 \quad A, a$ & 715 & $838 \quad A, a$ & $780 \quad B, b$ & $<0,0001$ \\
\hline P-valor & & 0,5676 & $<0,0001$ & 0,8681 & 0,0098 & \\
\hline MDP & COM & $639 \quad A, a$ & $316 \quad B, a$ & $637 \quad A, a$ & $627 \quad A, a$ & $<0,0001$ \\
\hline MDP & SEM & $618 \quad A, a$ & $308 \quad \mathrm{~B}, \mathrm{a}$ & $616 \quad A, a$ & $614 \quad A, a$ & $<0,0001$ \\
\hline P-valor & & 0,1875 & 0,6229 & 0,2043 & 0,4353 & \\
\hline Erro & \multicolumn{6}{|l|}{11,48} \\
\hline Padrão & & & & & & \\
\hline
\end{tabular}

Médias seguidas pela mesma letra minúscula na coluna e maiúscula na linha não diferem entre si pelo teste $\mathrm{F}(\mathrm{P}<0,05)$. 
No ensaio de envelhecimento acelerado APA D1, os compósitos convencionais MDP de madeira e resina de uréia-formaldeído não apresentaram diferença entre os valores de densidade aparente dos compósitos revestidos e não revestidos. Nesse caso, a resina não garantiu a preservação da densidade aparente. Isso se justifica pelo inchamento em espessura e perda de massa que os compósitos tiveram durante as condiçóes de estresse a que foram submetidos. Segundo Gunduz et al. (2009), as propriedades químicas e físicas da madeira sofrem mudanças permanentes durante o seu aquecimento, e sua estrutura é alterada,o que se explica principalmente em razão da degradação da hemicelulose. As mudanças continuam à medida que a temperatura é incrementada durante os processos de aquecimento. Como resultado disso, a espessura, assim como a densidade, diminui devido à redução do conteúdo de umidade. Visto que as mudanças na hemicelulose modificam o desempenho da madeira, a absorção de água é reduzida e qualquer proporção de água que penetre na madeira vai ser evaporada. Esse fenômeno foi observado nos corpos de prova do BCP sem revestimento superficial para o caso da condição C2, em que a densidade reduziu $8,1 \%\left(780 \mathrm{~kg} / \mathrm{m}^{3}\right)$; nesse caso, os painéis com revestimento superficial não apresentaram redução na densidade, indicando a efetividade do uso da resina poliuretana à base de óleo de mamona como revestimento superficial. Por outro lado, quando a temperatura aumenta junto com a umidade no ensaio APA D1, observa-se, em todos os materiais, a redução da densidade aparente de 7,9\% (BCP-CR), 15,7\% (BCP-SR). Para o caso do painel convencional, a diminuição foi de 50, 5\% (MDP-CR) e 50,1\% (MDP$\mathrm{SR})$, gerada possivelmente pelo aumento da espessura e perda de adesão das partículas de madeira quando exposta à água e a altas temperaturas no ensaio.

\subsection{Propriedades Mecânicas}

A Tabela 8 lista as análises estatísticas ANOVA avaliando o efeito do material (BCP ou MDP), do revestimento superficial e das condiçóes de envelhecimento acelerado [referência (0 ciclos), APA, C1 e C2] sobre as propriedades mecânicas: Módulo de Ruptura (MOR), Módulo de Elasticidade (MOE) e Adesão Interna (AI). Além disso, são analisadas as influências das interaçóes duplas e tripla entre o material, o revestimento superficial e as condiçóes de envelhecimento acelerado. As análises mostram que a posição de extração dos corpos-de-prova no painel não interfere nos valores das propriedades mecânicas. No entanto, o tipo de material (BCP/ 
MDP), o revestimento superficial e as condiçôes de envelhecimento acelerado (0 Ciclos, APA D1, C1 e C2) interferiram nas propriedades mecânicas dos corpos de prova. Foi constatado que as interaçôes dupla e tripla interferem significativamente sobre as propriedades mecânicas, ou seja, as variáveis náo são independentes.

Tabela 8. Análise de variância para propriedades mecânicas.

\begin{tabular}{llll}
\hline \multirow{2}{*}{ Fonte de variação } & MOR & MOE & Al \\
\cline { 2 - 4 } & P-valor & P-valor & P-valor \\
\hline Material (BDP/MDP) & $<0.0001^{* *}$ & 0,1349 & $<.0001^{* *}$ \\
\hline Revestimento Superficial (Com/Sem) & $0.0002^{* *}$ & $0,0002^{* *}$ & $<.0001^{* *}$ \\
\hline Condicão (O Ciclos, APA D1, C1, C2) & $<.0001^{* *}$ & $<.0001^{* *}$ & $<.0001^{* *}$ \\
\hline $\mathrm{M} \times \mathrm{R}$ & 0,7964 & 0,3035 & 0,4049 \\
\hline $\mathrm{M} \times \mathrm{C}$ & $<.0001^{* *}$ & $<.0001^{* *}$ & $<.0001^{* *}$ \\
\hline $\mathrm{R} \times \mathrm{C}$ & 0,2492 & 0,8328 & $0,0007^{* *}$ \\
\hline $\mathrm{M} \times \mathrm{R} \times \mathrm{C}$ & 0,5978 & 0,2872 & $0,0243^{*}$ \\
\hline $\mathrm{P}<0,001$ e $\mathrm{P}<0,05$ significativo a $1 \%$ (**) $^{*}$ e $5 \%$ (*) $^{*}$ respectivamente. M: Material; R: Revestimento \\
superficial; C: Condições de envelhecimento acelerado. & &
\end{tabular}

Constatou-se que existe influência da interação tripla (material, revestimento superficial e condições de envelhecimento acelerado) sobre a adesão interna (AI) do material, ou seja, essa resposta depende da combinação entre esses fatores mencionados acima. Entretanto, o MOR e MOE são dependentes dos efeitos combinados entre os fatores: material e condiçóes de envelhecimento acelerado. Adicionalmente, as análises estatísticas indicaram que há uma diferença significativa entre os corpos-de-prova com e sem revestimento superficial, independentemente do tipo de material e das condiçóes de envelhecimento acelerado. A Tabela 9 apresenta os resultados obtidos nas propriedades mecânicas para os painéis de bagaço de cana-deaçúcar e MDP nas diferentes condiçôes de envelhecimento acelerado.

A porcentagem retida da AI, após o ensaio de envelhecimento APA D1, diminuiu para todos os corpos-de-prova, com e sem revestimento superficial. Os corpos-de-prova de MDP, após o envelhecimento acelerado APA D1, sofreram uma significativa degradação em relação aos de BCP com base no comportamento das propriedades mecânicas: MOR e MOE. O material de referência MDP apresenta, antes do envelhecimento acelerado, um menor valor de $\mathrm{AI}$ em relação ao $\mathrm{BCP}$. O material MDP é constituído de três camadas 
de partículas com tamanhos diferentes, sendo a camada interna constituída de partículas mais grosseiras e as camadas externas de partículas mais finas. Desse modo, não há completa aderência entre as partículas nas interfaces das camadas, ou seja, existe uma maior porosidade nas interfaces.

Tabela 9. Propriedades mecânicas dos painéis particulados antes e após os ensaios de envelhecimento acelerado.

\begin{tabular}{|c|c|c|c|c|c|c|c|c|}
\hline \multirow[t]{3}{*}{ Material } & \multirow{3}{*}{$\begin{array}{l}\text { Revestimento } \\
\text { Superficial }\end{array}$} & \multirow{3}{*}{$\begin{array}{l}\text { Referência } \\
\text { (0 Ciclos) } \\
\text { Al (MPa) }\end{array}$} & \multirow{2}{*}{\multicolumn{2}{|c|}{$\begin{array}{l}\text { APA } \\
\text { D1 }\end{array}$}} & \multirow{2}{*}{\multicolumn{2}{|c|}{ C1 }} & \multirow{2}{*}{\multicolumn{2}{|c|}{$\mathrm{C} 2$}} \\
\hline & & & & & & & & \\
\hline & & & $\begin{array}{l}\mathrm{Al} \\
(\mathrm{MPa})\end{array}$ & $\begin{array}{l}\text { Al } \\
\text { Retido } \\
(\%)\end{array}$ & $\begin{array}{l}\text { Al } \\
(\mathrm{MPa})\end{array}$ & $\begin{array}{l}\text { Al } \\
\text { Retido } \\
(\%)\end{array}$ & $\begin{array}{l}\text { Al } \\
(\mathrm{MPa})\end{array}$ & $\begin{array}{l}\text { Al } \\
\text { Retido } \\
\text { (\%) }\end{array}$ \\
\hline BCP & COM & 0,95 & 0,67 & 71 & 0,88 & 93 & 0,76 & 80 \\
\hline BCP & SEM & 1,02 & 0,47 & 46 & 0,97 & 95 & 0,52 & 51 \\
\hline MDP & COM & 0,60 & 0,02 & 4 & 0,56 & 92 & 0,54 & 89 \\
\hline MDP & SEM & 0,52 & 0,00 & 0 & 0,46 & 88 & 0,40 & 77 \\
\hline \multicolumn{2}{|c|}{ Erro padrão } & 0,044 & & & & & & \\
\hline
\end{tabular}

\begin{tabular}{lllllllll}
\hline Material & $\begin{array}{l}\text { Revestimento } \\
\text { Superficial }\end{array}$ & & $\begin{array}{l}\text { MOE (GPa) } \\
\text { (GPa) }\end{array}$ & $\begin{array}{l}\text { MOE } \\
\text { Retido } \\
\text { (\%) }\end{array}$ & $\begin{array}{l}\text { MOE } \\
\text { (GPa) }\end{array}$ & $\begin{array}{l}\text { MOE } \\
\text { Retido } \\
\text { (\%) }\end{array}$ & $\begin{array}{l}\text { MOE } \\
\text { (GPa) }\end{array}$ & $\begin{array}{l}\text { MOE } \\
\text { Retido } \\
\text { (\%) }\end{array}$ \\
\hline BCP & COM & 2,15 & 1,57 & 73 & 2,28 & 100 & 2,15 & 100 \\
\hline BCP & SEM & 2,07 & 1,22 & 59 & 1,97 & 95 & 1,90 & 92 \\
\hline MDP & COM & 2,73 & 33,3 & 1 & 2,65 & 97 & 2,83 & 100 \\
\hline MDP & SEM & 2,52 & 49,0 & 2 & 2,54 & 100 & 2,56 & 100 \\
\hline Erro padrão & 0,069 & & & & & & \\
\hline
\end{tabular}

\begin{tabular}{lllllllll}
\hline Material & $\begin{array}{l}\text { Revestimento } \\
\text { Superficial }\end{array}$ & & $\begin{array}{l}\text { MOR (MPa) } \\
\text { (MPa) } \\
\text { (MOR }\end{array}$ & $\begin{array}{l}\text { MOR } \\
\text { Retido } \\
\text { (\%) }\end{array}$ & $\begin{array}{l}\text { MOR } \\
\text { (MPa) }\end{array}$ & $\begin{array}{l}\text { MOR } \\
\text { Retido } \\
(\%)\end{array}$ & $\begin{array}{l}\text { MOR } \\
\text { (MPa) }\end{array}$ & $\begin{array}{l}\text { MOR } \\
\text { Retido } \\
(\%)\end{array}$ \\
\hline BCP & COM & 21,7 & 20,0 & 90 & 20,2 & 93 & 21,7 & 100 \\
\hline BCP & SEM & 17,9 & 16,8 & 94 & 17,9 & 100 & 17,9 & 100 \\
\hline MDP & COM & 20,7 & 0,4 & 2 & 18,3 & 89 & 20,7 & 100 \\
\hline MDP & SEM & 15,6 & 0,5 & 3 & 15,9 & 100 & 15,6 & 100 \\
\hline Erro padrão & 0,82 & & & & & & \\
\hline
\end{tabular}


Como consequência, o MDP apresenta uma maior absorção de água, como indica a Figura 12. O aumento do inchamento na espessura do MDP corrobora com aumento da absorção de água e promove uma diminuição da resistência da adesáo interna de partículas, como ilustra a Figura 12b. Isso pode ser explicado pelo uso da resina à base de uréia-formaldeído (UF) nos painéis comercias MDP, que apresenta baixa resistência à umidade (VALARELLI et al., 2013; IWAKIRI 2005). A diferença da resina poliuretana à base de óleo de mamona é que ela apresenta, entre outras vantagens ambientais e técnicas, maiores resistências físicas e mecânicas, principalmente resistência à umidade (SILVA et al., 2013).

Os corpos de prova com e sem revestimento superficial foram testados nas condiçôes de envelhecimento acelerado $\mathrm{C} 1$ (efeito da umidade relativa de $93 \%$ por $8 \mathrm{~h}$ ) e C2 (efeito da temperatura de $82^{\circ} \mathrm{C}$ por $14,5 \mathrm{~h}$ ). Observouse que, na condição $\mathrm{C} 1$, o valor retido da $\mathrm{AI}, \mathrm{MOR}$, e $\mathrm{MOE}$ foi acima de $85 \%, 95 \%$ e $89 \%$, respectivamente, para todos os materiais, ou seja, a alta umidade relativa por $8 \mathrm{~h}$ não foi suficiente para comprometer o desempenho mecânico do compósito. No entanto, na condição C2, o compósito BCP sem revestimento superficial sofreu maior degradação ao observar a resistência da adesão interna, em relação ao compósito ou ao outro material MDP com proteção. Observou-se que, na condição com umidade relativa de $93 \%$ por 8 h (UR93) e com temperatura a $82^{\circ} \mathrm{C}$ por $14,5 \mathrm{~h}$ (T82), o valor retido para da MOE foi acima de $90 \%$ e $95 \%$, respectivamente, para ambos os materiais, nas duas condiçôes de revestimento. Isso significa que as condiçôes de alta umidade relativa por $8 \mathrm{~h}$ e alta temperatura durante $14 \mathrm{~h}$, avaliadas separadamente, não foram suficientes para comprometer o desempenho mecânico do compósitos e os danos ocasionados são gerados pelos efeitos combinados dos agentes de degradação. 

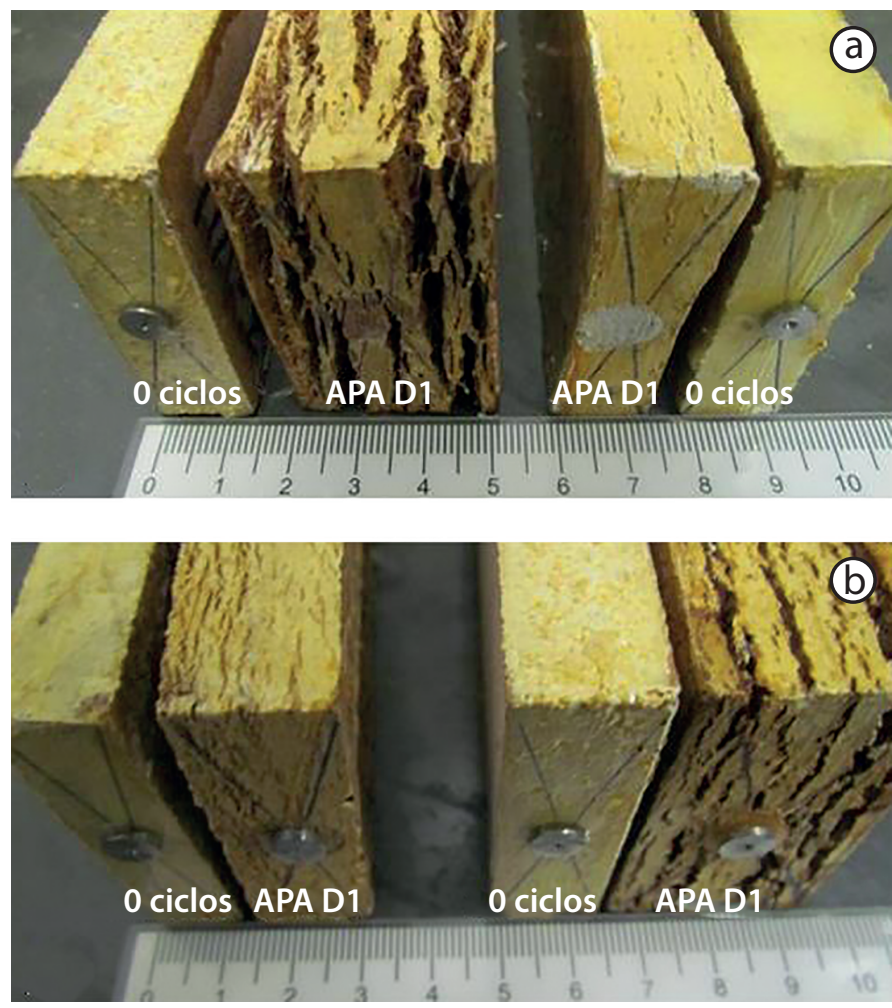

Figura 12. Corpos-de-prova de MDP e BCP sem (a) e com (b) revestimento superficial.

Kojima et al. (2010) realizaram o ensaio de envelhecimento acelerado APA D1 com painéis particulados de madeira com resina à base de fenolformaldeído (PF) e de isocianato (MDI) e determinaram, respectivamente, valores retidos de AI de $27 \%$ e acima de $70 \%$. Esses resultados indicam o efeito da resina sobre as propriedades mecânicas após o envelhecimento acelerado. A Figura 13 apresenta os painéis de bagaço de cana-de-açúcar após o ensaio de envelhecimento acelerado APA D1. Podem-se observar, na Figura 13a, painéis sem envelhecimento em que a estrutura inicial e disposição das partículas de bagaço de cana-de-açúcar estão recobertos por resina. Na Figura 13b, pode-se observar que os painéis de bagaço de cana com revestimento, após o ensaio de envelhecimento acelerado APA D1, apresentaram pouca degradaçáo e a adesão interna das partículas ainda foi visível. A Figura $13 \mathrm{~b}$ mostra um incremento nos espaços entre as partículas e, por consequência, a diminuição da ligação interna entre elas devido aos agentes de degradação, como a água, a 
umidade e a temperatura, aos quais os corpos de prova estiveram submetidos. Os compósitos que receberam revestimento superficial apresentaram uma porcentagem menor de absorção de água e de inchamento de espessura em relação aos compósitos sem revestimento.
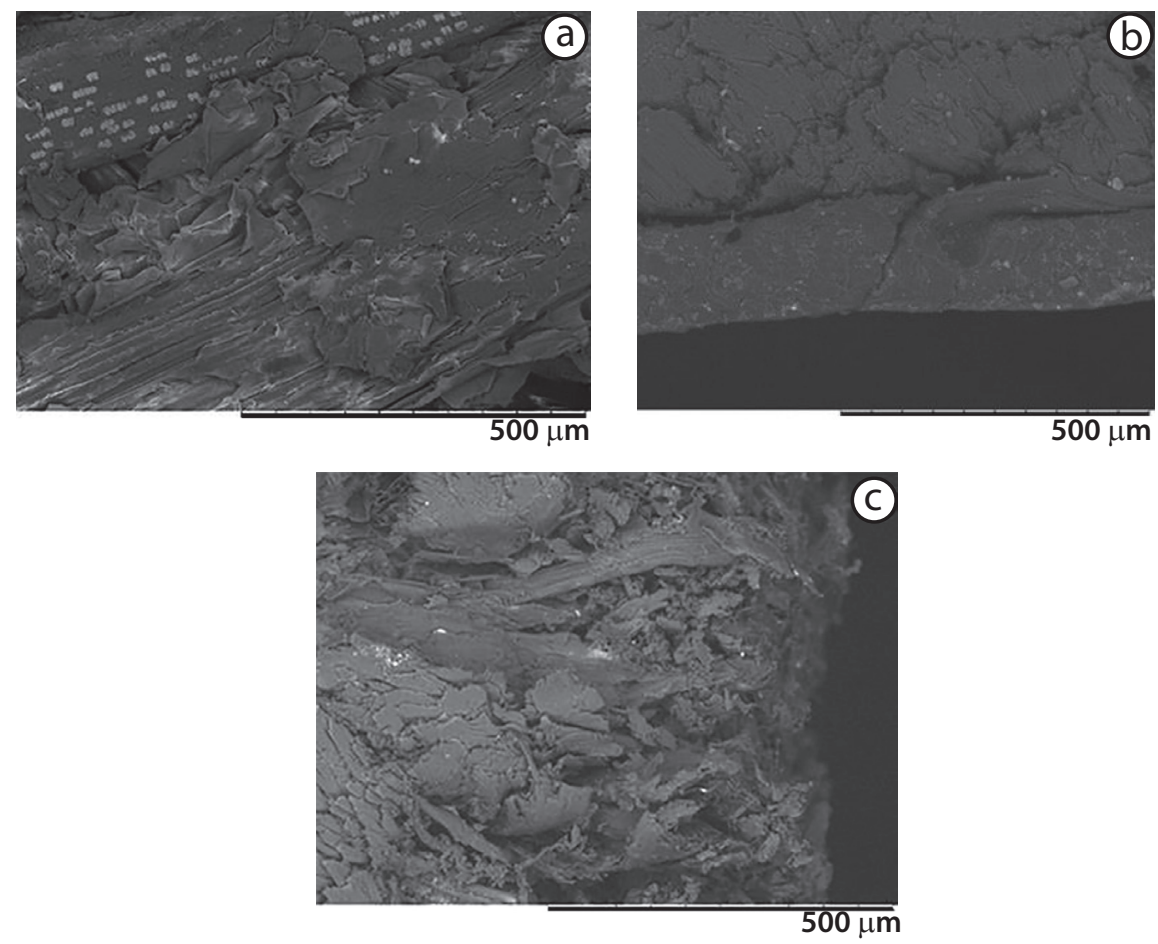

Figura 13. Imagens MEV de Painéis de bagaço de cana-de-açúcar (BCP) a) Inicial, b) BCP Com Revestimento e c) BCP Sem Revestimento após ensaios de envelhecimento acelerado APA D1.

Assim, para o caso dos painéis de partículas de bagaço de cana-de-açúcar (BCP), a fonte de variação associada ao uso do revestimento superficial influencia de forma direta o desempenho e a durabilidade do material.

\subsection{Envelhecimento Natural}

Nesta seção, são apresentados os resultados obtidos para os períodos de 3 e 6 meses de envelhecimento natural dos corpos-de-prova de painéis de bagaço de cana-de-açúcar (BCP) e de madeira (MDP) . 


\subsubsection{Propriedades Físicas}

\subsubsection{Densidade Aparente}

Os resultados dos efeitos das condições ambientais de temperatura, umidade relativa e precipitação sobre a densidade nos painéis de bagaço de cana-de-açúcar (BCP) e painéis comerciais particulados de mediana densidade de madeira (MDP) apresentaram interação entre os tipos de materiais (BCP, MDP), o revestimento superficial (Com e Sem) e o tempo de exposição natural (0, 3 e 6 meses) com nível de significância P-valor < 0,0001.

Ao se avaliar o efeito do revestimento superficial, observa-se que os valores de densidade aparente mostraram diferença significativa em ambos os materiais, com revestimento superficial (Figura 14a) e sem revestimento (Figura 14b), em cada um dos tempos de exposição ao envelhecimento natural avaliados. Portanto, a resina poliuretana à base de óleo de mamona utilizada como revestimento superficial, além de conferir resistência nas propriedades mecânicas, melhora o comportamento dos materiais em condições ambientais adversas, principalmente a umidade (SILVA et al., 2008) (Figura 14).

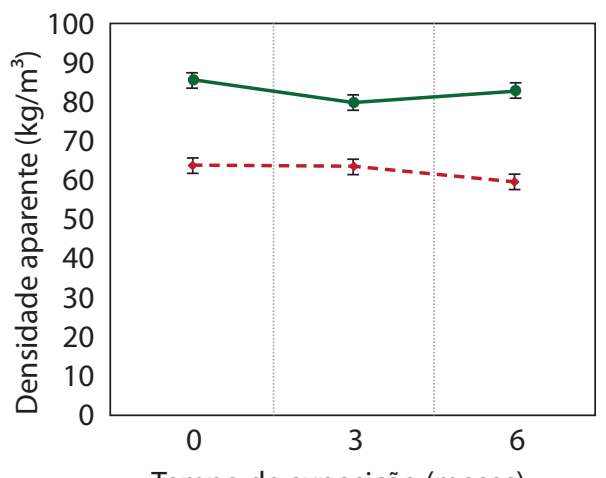

Tempo de exposição (meses)

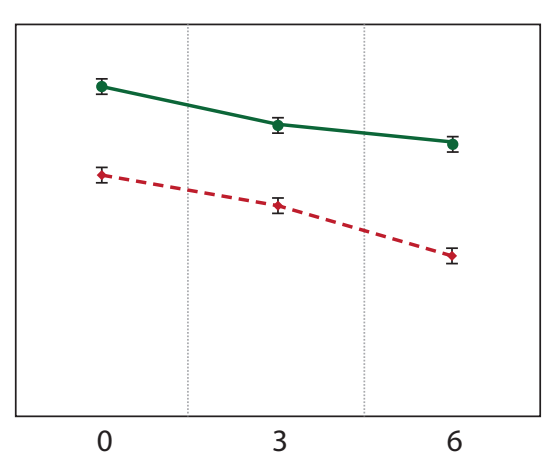

Tempo de exposição (meses)

$$
\rightarrow \text { BCP } \quad \rightarrow-\cdot M D P
$$

Figura 14. Efeito do revestimento superficial e tempo de exposição ao envelhecimento natural na densidade aparente $\left(\mathrm{kg} / \mathrm{m}^{3}\right)$ dos materiais: a) com revestimento b) sem revestimento

Segundo Kojima \& Suzuki (2011), as condiçôes ambientais que podem afetar a deterioração dos painéis à base de madeira são temperatura, 
precipitação, radiação solar e vento, dentre outras. Para o caso deste estudo, o tempo de análise correspondeu aos meses entre julho e dezembro, correspondendo à parte final da estação de inverno, primavera e começo do verão. Durante os três primeiros meses, foi apresentada uma precipitação de $120 \mathrm{~mL}$, que, no período seguinte, aumentou para $757 \mathrm{~mL}$. Após os três primeiros meses, observou-se a diminuição nos valores da densidade em ambos os materiais. No entanto, para aqueles com revestimento superficial, a densidade foi mantida sem apresentar diferença estatística durante o período de exposição. Analisando o efeito das condiçôes ambientais em cada um dos materiais, notou-se que tanto os painéis BCP como os MDP mantiveram a densidade ao longo dos 6 meses de exposição, embora os materiais sem revestimento apresentassem uma diminuição. No caso dos painéis BCP sem revestimento, a diminuição da densidade foi observada a partir dos três meses, e essa densidade foi mantida até os 6 meses. Para o caso dos painéis MDP sem revestimento, o decrescimento da densidade foi observado desde os três meses. Esse resultado pode ser explicado pelo aumento do inchamento e perda de massa. Menezzi et al. (2008), após 8 meses de exposição, observaram que os fatores ambientais tiveram um efeito negativo nas propriedades físicas e mecânicas, atribuindo esse fato ao aumento do inchamento causado pelas mudanças nas condiçôes ambientais a que foram expostos os materiais.

Tabela 10. Desdobramento Material * Revestimento * Tempo de exposição natural para densidade aparente (\%).

\begin{tabular}{|c|c|c|c|c|c|c|c|c|}
\hline \multirow[t]{3}{*}{ Material } & \multirow{3}{*}{$\begin{array}{l}\text { Revestimento } \\
\text { Superficial }\end{array}$} & \multicolumn{7}{|c|}{ Tempo de exposição ao envelhecimento natural (meses) } \\
\hline & & \multicolumn{2}{|l|}{0} & \multicolumn{2}{|l|}{3} & \multicolumn{2}{|l|}{6} & \multirow[t]{2}{*}{$\mathrm{P}$-valor } \\
\hline & & \multicolumn{6}{|c|}{ Densidade Aparente $\left(\mathrm{kg} / \mathrm{m}^{3}\right)$} & \\
\hline BCP & COM & 859 & $A, a$ & 802 & $\mathrm{~B}, \mathrm{a}$ & 831 & $A B, a$ & 0,015 \\
\hline BCP & SEM & 849 & $\mathrm{~A}, \mathrm{a}$ & 749 & $\mathrm{~B}, \mathrm{~b}$ & 704 & $\mathrm{~B}, \mathrm{~b}$ & $<0,0001$ \\
\hline P-valor & & \multicolumn{2}{|c|}{0,6265} & \multicolumn{2}{|c|}{0,0057} & \multicolumn{2}{|c|}{$<.0001$} & \\
\hline MDP & COM & 639 & $A, a$ & 636 & $\mathrm{~A}, \mathrm{a}$ & 598 & $\mathrm{~A}, \mathrm{a}$ & 0,0603 \\
\hline MDP & SEM & 618 & $A, a$ & 544 & $\mathrm{~B}, \mathrm{~b}$ & 412 & $c, b$ & $<0,0001$ \\
\hline \multicolumn{2}{|l|}{ P-valor } & \multicolumn{2}{|c|}{0,2616} & \multicolumn{2}{|c|}{$<0,0001$} & \multicolumn{2}{|c|}{$<0,0001$} & \\
\hline Erro Padrão & 13,4726 & & & & & & & \\
\hline
\end{tabular}

Médias seguidas pela mesma letra maiúscula na linha não diferem entre si pelo teste Tukey $(P<0,05)$ Médias seguidas pela mesma letra minúscula na coluna não diferem entre si pelo teste $F(P<0,05)$. 


\subsubsection{Absorção de Água (AA) e Inchamento na Espessura (IE) Residual}

Após 3 e 6 meses de exposição dos corpos-de-prova ao envelhecimento natural, foi determinada a porcentagem de absorção de água e de inchamento residual nos materiais. A Figura 15a apresenta os resultados de absorção de água e inchamento de espessura residual, após o envelhecimento natural, assim como a influência de alguns parâmetros metereológicos em função do tempo exposição. Após os três primeiros meses (julho a setembro de 2012), os materiais submetidos a condiçôes naturais, a variaçôes de temperaturas, a períodos de chuvas e ao aumento progressivo da umidade relativa tiveram o aumento do inchamento na espessura e a delaminaçáo favorecida, diminuindo a resistência de adesão interna das partículas e, por conseguinte, outras propriedades mecânicas. Entre outubro a dezembro de 2012, os parâmetros climatológicos indicaram aumento da precipitação de chuva e da temperatura.

A absorção de água variou significativamente em função da precipitação, principalmente para os corpos de prova sem revestimento superficial, independentemente do material. A taxa de absorção de água aumenta de acordo com a quantidade de madeira e/ou fibras no compósito particulado. $\mathrm{Ou}$ seja, quando o conteúdo de partículas de madeira é aumentado no composto, o número de grupos livres $\mathrm{OH}$ da celulose da madeira e/ou fibras aumenta. Com isso, observa-se um ganho de peso dos compostos ao entrarem em contato com a água, pela formação de pontes de hidrogênio. Naturalmente, o compósito com menor conteúdo de partículas de madeira e/ou fibras atinge o equilíbrio de massa mais rapidamente. Nos materiais expostos neste estudo, o conteúdo de materiais celulósicos foi de 56,2\% para os corpos-de-prova de BCP e de 51,7\% para os de MDP. Além dessa diferença, outros fatores podem influenciar os resultados de absorção de água, tais como, tipo de resina e revestimento superficial, porosidade interna do material e morfologia das partículas (BOND, 2006).

A Figura 15b mostra a variação do inchamento na espessura dos corpos de prova $\mathrm{BCP}$ e MDP, com e sem revestimento superficial, no período de exposição ao ar livre. Pode-se observar o aumento de inchamento na espessura em todos os materiais expostos. Nos corpos-de-prova com revestimento superficial (BCP CR) e (MDP CR), o inchamento na espessura aumentou em até $15 \%$ e nos sem revestimento (BCP SR) e (MDP SR), acima de $20 \%$. Esse resultado pode ser atribuído ao período de chuva apresentado durante os 
três últimos meses, como é mostrado na Figura 15d, assim como o aumento da umidade relativa gerando a degradação do material. Okuda e Sato (2008), estudaram painéis tipo binderless confeccionados a $180^{\circ} \mathrm{C}$, expostos ao ar livre, em maio de 2004, em Tokyo, Japão (35 42' 59.0" N, 139 45' 40.6" E), durante 23 meses, e encontraram valores de inchamento na espessura abaixo de $10 \%$ durante os três primeiros meses, com um índice pluviométrico de $285 \mathrm{~mm}$, nesse período. No caso de Pirassununga SP, Brasil, esse índice foi de $572 \mathrm{~mm}$, o que possibilitou o aumento do inchamento nos materiais expostos.
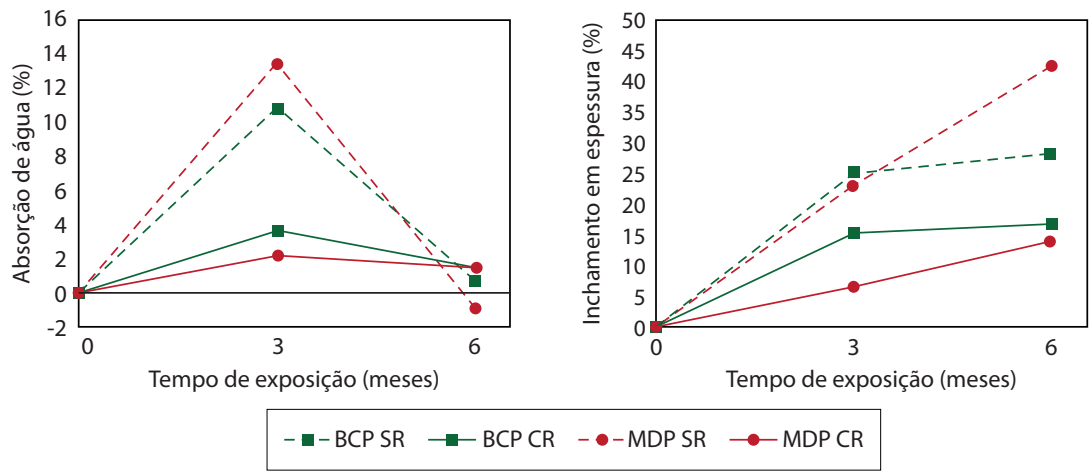

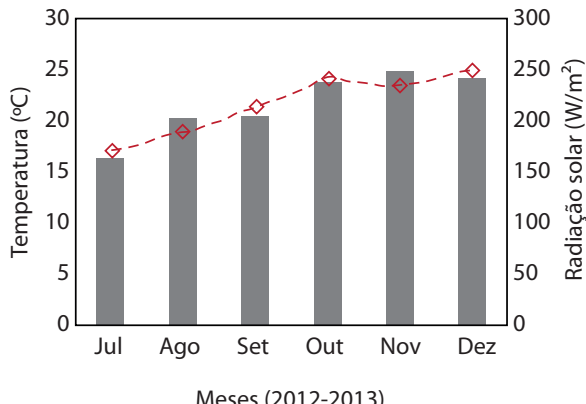

Meses (2012-2013)

— Radiação solar $\quad-\diamond-$ Temperatura

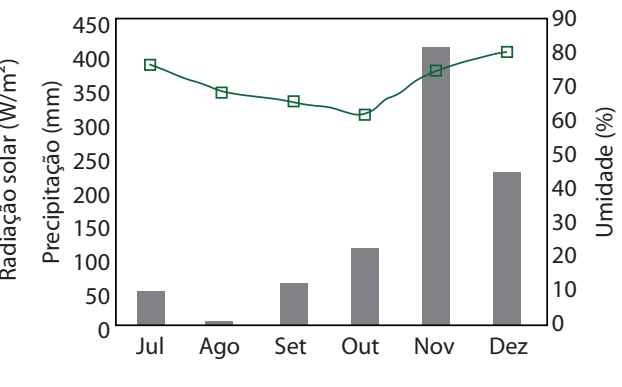

Meses (2012-2013)

— Precipitação $\square$ Umidade

Figura 15. (a) Gráficos de absorção de água e (b) de inchamento na espessura em função do tempo de exposição. Gráficos de parâmetros meteorológicos (c) Radiação solar e temperatura e (d) precipitação e umidade relativa em função do tempo de exposição dos materiais.

Com o aumento precipitação após os três primeiros meses, o aumento da temperatura e da umidade, foi identificado um aumento na delaminação dos materiais, incrementando, da mesma forma, o inchamento. Foi observada 
delaminação na borda dos corpos de prova depois de 3 meses de exposição ao ar livre, em maior proporção nos corpos-de-prova sem revestimento superficial. $\mathrm{O}$ mesmo ocorreu com materiais após 6 meses de exposição. No entanto, observam-se diferenças significativas entre os corpos-de-prova sem revestimento, MDP SR e BCP SR, que apresentaram valores de inchamento de $43 \%$ e $29 \%$ respectivamente. A mesma tendência ocorreu para os materiais com revestimento superficial, ou seja, o material MDP CR apresentou maior inchamento na espessura em comparação aos materiais BCP CR. De forma geral, os corpos-de-prova de bagaço de cana-de-açúcar apresentaram melhor desempenho físico em relação ao MDP. Esses resultados serão posteriormente reavaliados, após um ano de exposição na estação de envelhecimento natural.

\subsubsection{Propriedades Mecânicas MOR, MOE e Al}

Para as três propriedades mecânicas, foram encontradas interaçóes significativas entre: tipo de material (BDP/MDP), revestimento superficial (Com/Sem) e o tempo de exposição ao ar livre (3 e 6 meses) em relação aos corpos-de-prova controle (referência) com p-valor 0,0015 (MOR), <0,0001** $(\mathrm{MOE})$ e $0,0053^{* *}(\mathrm{AI})$. Esse resultado mostra que as fontes de variação analisadas não atuam independentemente.

Os resultados sugerem que as condiçóes climáticas a que foram submetidos os materiais influenciaram na adesão interna (AI). Observa-se que a AI retida dos corpos-de-prova submetidos à exposição natural diminuiu em função do tempo. Menezzi et al. (2008) avaliaram painéis estruturais OSB durante 8 meses, em Brasília (Brasil), e atribuem esse comportamento ao estresse gerado durante a exposição, isto é, o encolhimento e inchaço do material e a quebra da ligação do adesivo, o qual diminui significativamente a adesão interna. Com base nas consideraçóes da análise estatística, nota-se que há uma diferença significativa entre os tipos de materiais e o fato de haver ou não a presença do revestimento superficial. Desse modo, após o período de três meses de exposição natural, os painéis com revestimento superficial (BCP CR) apresentaram resistência de adesão interna retida acima de 62\% em comparação com o índice de 50\% dos painéis de partículas de madeira nas mesmas condiçôes (MDP CR). Os painéis de bagaço de cana- de-açúcar sem revestimento superficial (BCP SR) apresentaram AI retida de 36\% e os de madeira sem revestimento (MDP SR) apresentaram o valor de $13 \%$. Essa diferença pode ser atribuída ao tipo de resina usada para aglomerar as 
partículas e/ou fibras. Após seis meses, os painéis de bagaço de cana-de-açúcar, com e sem revestimento, apresentaram melhor desempenho com relação à AI retida em comparaçáo ao material MDP.

A Figura 16 mostra a variação dos valores das propriedades mecânicas dos materiais, com e sem revestimento superficial, após o envelhecimento natural de 3 e 6 meses.
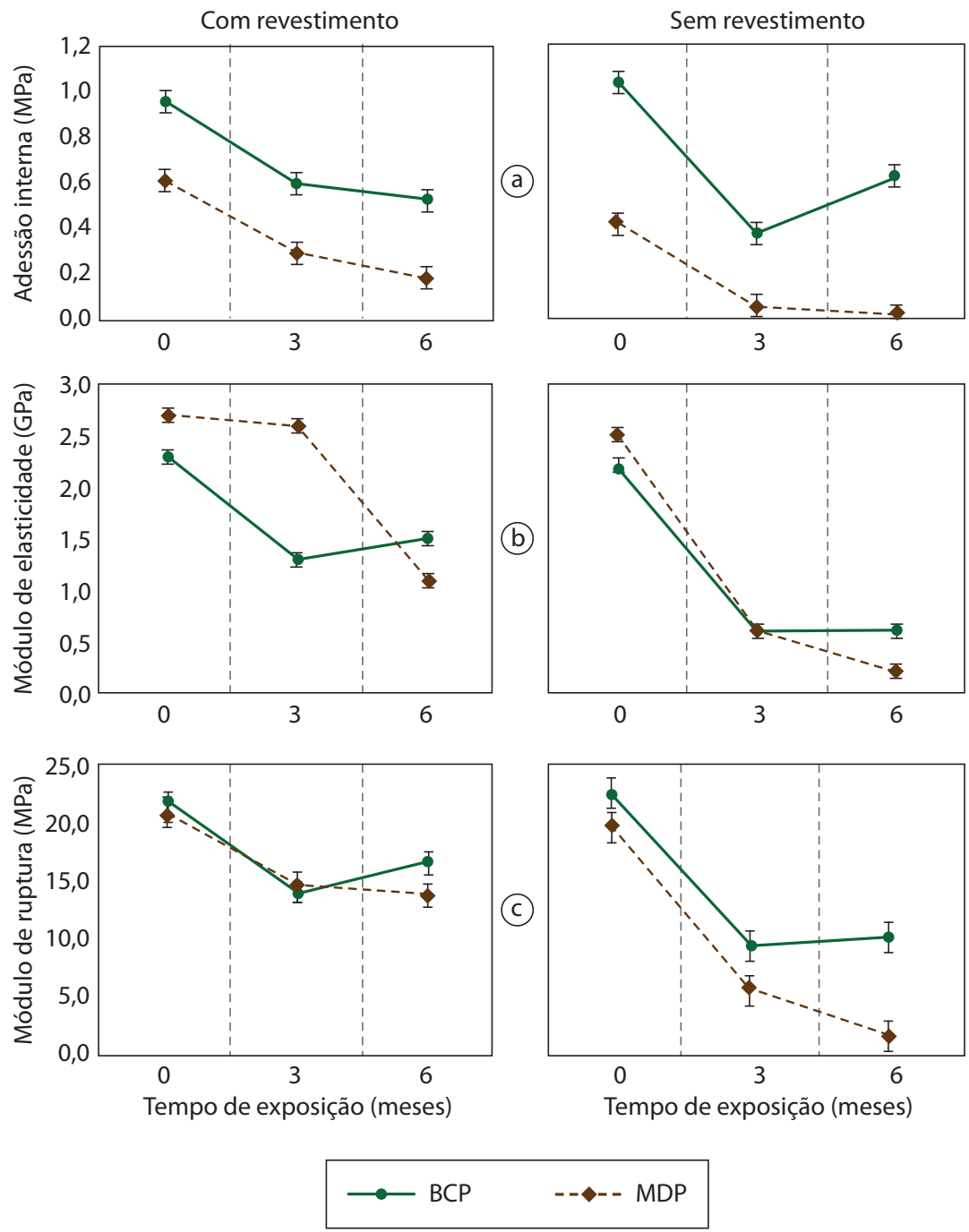

Figura 16. Efeito do revestimento superficial e do tempo de exposição ao envelhecimento natural nas propriedades mecânicas dos materiais: (a) $\mathrm{Al}$, (b) MOE e (c) MOR. 
O comportamento mecânico dos materiais é similar ao comportamento de outros tipos de materiais particulados. Kojima et al. (2012) estudaram painéis particulados (Particle board - PB), Oriented Strands Board (OSB), PlyWood (PW) e Medium Density Fiberboard (MDF) submetidos a 7 anos de exposição ao ar livre, em oito locais do norte e sul do Japão, entre abril de 2004 e março do 2011. Os pesquisadores constataram que a resistência de adesão interna depende do tipo de material, do revestimento superficial e do tempo de exposição ao ar livre.

O efeito do intemperismo por meio da radiação solar, temperatura e precipitação ocasionaram na superfície dos materiais revestidos com a resina poliuretana à base de óleo de mamona cavidades que permitiram o ingresso de água nos materiais, diminuindo os valores das propriedades. Okuda e Sato (2008) assinalam que a degradação superficial pode ocorrer principalmente devido aos efeitos combinados da luz ultravioleta e da precipitação e que esta pode ter uma influência na redução da adesão interna das partículas no material.

Após 6 meses, os painéis de bagaço de cana-de-açúcar, com e sem revestimento, apresentaram um melhor desempenho com relação à AI retida em comparação ao material MDP. Isso pode ser explicado pela ação de expansão da resina poliuretana de óleo de mamona que, como foi dito anteriormente, ocupa os poros entre as partículas.

Observou-se uma inversão do desempenho em relação ao tipo de material com revestimento superficial. Para o caso dos materiais sem revestimento, os materiais BCP SR conseguiram manter MOE retido em 41\%, enquanto os materiais MDP SR apresentaram o valor de 7\%, Tabela 11.

Segundo Liso et al. (2006), o desempenho do revestimento superficial na madeira depende da qualidade da madeira, do revestimento, dos detalhes de construção e dos impactos climáticos aos quais estão expostos. Nos painéis particulados de bagaço de cana-de-açúcar com revestimento (BCPCR), após os três primeiros meses, aparecem cavidades ocasionadas pelo rompimento da resina superficial, devido à ação da temperatura e radicação solar na resina, assim mesmo, pode ser observado o aparecimento inicial de alguns fungos emboloradores. Segundo Scheffer (1973), dentro das primeiras manifestações visíveis de deterioração por fungos, encontram-se uma superfície suave, falta de brilho e aparecimento de manchas apresentando uma descoloração irregularmente distribuída. 
Tabela 11. Valores médios e os retidos das propriedades mecânicas para painéis particulados sob envelhecimento natural.

\begin{tabular}{|c|c|c|c|c|c|c|}
\hline \multirow[t]{2}{*}{ Material } & \multirow{2}{*}{$\begin{array}{l}\text { Revestimento } \\
\text { Superficial }\end{array}$} & \multirow{2}{*}{$\begin{array}{l}\text { Referência } \\
\text { (0 meses) } \\
\mathrm{Al}(\mathrm{MPa})\end{array}$} & \multicolumn{2}{|l|}{3 meses } & \multicolumn{2}{|l|}{6 meses } \\
\hline & & & Al (MPa) & $\begin{array}{l}\text { Al Retida } \\
(\%)\end{array}$ & $\mathrm{Al}(\mathrm{MPa})$ & $\begin{array}{l}\text { Al Retida } \\
(\%)\end{array}$ \\
\hline BCP & COM & 0,95 & 0,59 & 62 & 0,53 & 55 \\
\hline BCP & SEM & 1,02 & 0,37 & 36 & 0,62 & 61 \\
\hline MDP & COM & 0,60 & 0,30 & 49 & 0,19 & 31 \\
\hline MDP & SEM & 0,52 & 0,07 & 13 & 0,03 & 6 \\
\hline \multicolumn{2}{|c|}{ Erro padrão } & \multicolumn{5}{|l|}{0,0455} \\
\hline Material & $\begin{array}{l}\text { Revestimento } \\
\text { Superficial }\end{array}$ & MOE (GPa) & $\begin{array}{l}\mathrm{MOE} \\
(\mathrm{GPa})\end{array}$ & $\begin{array}{l}\text { MOE } \\
\text { Retido } \\
(\%)\end{array}$ & $\begin{array}{l}\mathrm{MOE} \\
(\mathrm{GPa})\end{array}$ & $\begin{array}{l}\text { MOE } \\
\text { Retido } \\
(\%)\end{array}$ \\
\hline BCP & COM & 2,1 & 1,3 & 60 & 1,5 & 71 \\
\hline BCP & SEM & 2,1 & 0,6 & 30 & 0,5 & 27 \\
\hline MDP & COM & 2,7 & 2,6 & 97 & 1,1 & 41 \\
\hline MDP & SEM & 2,5 & 0,6 & 24 & 0,2 & 7 \\
\hline \multicolumn{2}{|c|}{ Erro padrão } & \multicolumn{5}{|l|}{0,06} \\
\hline Material & $\begin{array}{l}\text { Revestimento } \\
\text { Superficial }\end{array}$ & MOR (MPa) & $\begin{array}{l}\text { MOR } \\
(\mathrm{MPa})\end{array}$ & $\begin{array}{l}\text { MOR } \\
\text { Retido } \\
(\%) \\
\end{array}$ & $\begin{array}{l}\text { MOR } \\
(\mathrm{MPa})\end{array}$ & $\begin{array}{l}\text { MOR } \\
\text { Retido } \\
(\%) \\
\end{array}$ \\
\hline BCP & COM & 21,7 & 13,9 & 64 & 16,5 & 76 \\
\hline BCP & SEM & 17,9 & 7,5 & 42 & 8,0 & 45 \\
\hline MDP & COM & 20,7 & 14,6 & 71 & 13,7 & 67 \\
\hline MDP & SEM & 15,6 & 4,5 & 29 & 1,4 & 9 \\
\hline \multicolumn{2}{|c|}{ Erro padrão } & 0,971 & & & & \\
\hline
\end{tabular}

\section{Considerações Finais}

- No ensaio de envelhecimento acelerado baseado na norma APA D1 e para o caso dos painéis de MDP, o resultado mostra o sucesso parcial da proteção superficial no material particulado.

- O método de envelhecimento APA D1 mostrou-se como o ensaio que mais permitiu identificar os mecanismos de deterioração gerados pela temperatura e umidade a que foram submetidos os materiais. Os resul- 
tados obtidos indicam os painéis de bagaço de cana BCP com melhor desempenho em relação aos painéis comerciais de madeira. Além disso, o revestimento superficial melhorou ainda as propriedades dos painéis. Por outro lado, o revestimento superficial não se mostrou totalmente efetivo na proteção dos painéis MDP de madeira, uma vez que fatores como a água e a umidade penetraram pelas bordas do material, o efeito do adesivo à base de ureia formaldeído não conseguiu manter as propriedades físico-mecânicas iniciais.

- Os efeitos da temperatura e a umidade são de grande importância na análise da durabilidade dos materiais. Entretanto, a análise realizada nos compósitos, mediante uma exposição separada dos fatores de degradação, de acordo com ensaio de envelhecimento (UR93) e (T82), não indicou causas explícitas da degradação em curto tempo de exposição. Assim como os resultados encontrados pelos demais ensaios, em que os efeitos desses fatores são combinados.

- A relação existente entre os materiais de construção, as estruturas e o clima são complexas e faz-se necessário encontrar métodos mais precisos para avaliar o desempenho.

- Durante a exposição natural dos corpos foi evidenciada a influência do uso da resina poliuretana à base de óleo de mamona como revestimento superficial para ambos os materiais, na propriedade de densidade aparente. Assim, pode-se recomendar a utilização da resina como revestimento superficial, tendo em conta os agentes externos extremos de degradação (radiação solar, temperatura, precipitação e vento, por exemplo) a que foram submetidos os corpos-de-prova.

- Os efeitos gerados pelos agentes de degradação, como a água, a umidade relativa e a temperatura do ar, refletiram no aumento do inchamento e na absorção de água dos compósitos sem revestimento, pelo que se recomenda o uso de um revestimento superficial.

- Dentre as metodologias de envelhecimento acelerado utilizadas, o ensaio APA D1 representa, da melhor forma, a degradação dos materiais estabelecida pelos dois agentes de degradaçáo colocados de forma conjunta. As condiçóes isoladas $\mathrm{C} 1$ e $\mathrm{C} 2$ determinaram valores de retenção das propriedades mecânicas acima de $77 \%$, à exceção da AI para o BCP 
SR, que apresentou um comportamento similar ao ensaio de envelhecimento acelerado APA D1.

- Foi observada a diminuição do desempenho dos materiais, uma vez submetidos às condições de envelhecimento acelerado e natural, evidenciando que os mecanismos de transferência de umidade da madeira são altamente influenciados pelas condiçóes climáticas, que afetam as propriedades físicas e mecânicas em ambos os materiais.

- Em termos de retenção de MOR, MOE e AI, os painéis particulados de bagaço de cana-de-açúcar apresentaram maior porcentagem após o ensaio de envelhecimento acelerado APA D1 e o revestimento superficial protegeu parcialmente o material, ou seja, o tipo de resina utilizado na adesão das partículas foi preponderante para garantir a preservação parcial da resistência da adesão interna do material. Nesse caso, a resina à base de óleo de mamona foi mais eficaz do que ureia formaldeído ao se obervar o desempenho do material $\mathrm{BCP}$, sem e com revestimento superficial.

- O revestimento superficial realizado com a resina de mamona protegeu os painéis convencionais MDP sob as condiçôes de agentes isolados de degradação $\mathrm{C} 1$ e C2, permitindo valores de retenção das propriedades mecânicas de MOR e MOE acima de 89\%. Conclui-se, dessa maneira, que a degradação no material é gerada pela ação conjunta de vários agentes.

- Em ambos os materiais, o BCP apresentou melhor rigidez após o tempo de exposição, considerando o valor de $\mathrm{MOE}$, devido principalmente à açáo da resina poliuretana à base de óleo de mamona, utilizada como adesivo das partículas. Os materiais com revestimento superficial apresentaram melhor desempenho físico-mecânico.

- Os resultados sugerem que as condiçóes climáticas a que foram submetidas os materiais influenciaram o desempenho mecânico dos corpos-de-prova, sendo que aqueles que não foram revestidos apresentaram porcentagem de retenção menor do que os corpos-de-prova revestidos. No entanto, o painel de bagaço de cana apresentou melhoria no desempenho após 6 meses. 
- Em ambos os materiais MDP e BCP sem revestimento superficial, o BCP apresentou um melhor comportamento mecânico, após o tempo de exposição, para MOR, MOE e AI. Fato que pode derivar da ação da resina poliuretana de óleo de mamona utilizada como adesivo nos painéis de bagaço de cana-de-açúcar em comparação com a resina de ureia formaldeído.

- Pesquisas de campo com maiores tempos de exposição ao intemperismo natural e ensaios laboratoriais são necessários para melhorar a confiabilidade dos índices climáticos, incluindo medidas de taxas de decaimento em diferentes condiçôes climáticas e diferentes tipos de madeira ou outro material particulado.

\section{Referências Bibliográficas}

AMERICAN SOCIETY FOR TESTING AND MATERIALS. ASTM E632-82 (1996), Standard Practice for Developing Accelerated Tests to Aid Prediction of the Service Life of Building Components and Materials (Withdrawn 2005), ASTM International, West Conshohocken, PA, 1988.

AMERICAN SOCIETY FOR TESTING AND MATERIALS. ASTM D 1435 Standard Practice for Outdoor Weathering of Plastics, Philadelphia, 5 p. 1994.

AMERICAN SOCIETY FOR TESTING AND MATERIALS. ASTM E 632 Developed accelerated test $t$ aid prediction of the service life of building components and materials, Philadelphia, p. 102 - 107, 1996.

AMERICAN SOCIETY FOR TESTING AND MATERIALS. ASTM D 1037 Standard test methods for evaluating properties of wood-based fiber and particle panel materials. Philadelphia, 1996. p. 137-166.

AMERICAN SOCIETY FOR TESTING AND MATERIALS. ASTM D 2017-05 Accelerated Laboratory test of natural decay resistence of woods. Pennsylvania p. 1-5.2005. AMERICAN SOCIETY FOR TESTING AND MATERIALS. ASTM D-2017-2005 Accelerated laboratory test of natural decay resistence of woods. Philadelphia, 2005. 5 p. AMERICAN SOCIETY FOR TESTING AND MATERIALS. ASTM D-5590 Standard Test Method for Determining the Resistance of Paint Films and Related Coatings to Fungal Defacement by Accelerated Four-Week Agar Plate Assay, ASTM International, West Conshohocken, PA, 2010.

AMERICAN SOCIETY FOR TESTING AND MATERIALS. ASTM D 3273-12 Resistence to growth of mold on the surface of interior coatings in na environmental chamber. Pennsylvania p. 1-8. 2012. 
AMERICAN SOCIETY FOR TESTING AND MATERIALS. ASTM D 3273-12 Resistence to growth of mold on the surface of interior coatings in na environmental chamber. Pennsylvania, 2012. p. 1-8.

AMERICAN SOCIETY FOR TESTING AND MATERIALS. ASTM D-5590 Standard Test Method for Determining the Resistance of Paint Films and Related Coatings to Fungal Defacement by Accelerated Four-Week Agar Plate Assay.

AMERICAN SOCIET FOR TESTING AND MATERIALS. ASTM G21-15 - Standard practice for determining resistance of synthetic polymeric materials to fungi. Philadelphia, 2015. 6 p.

AMERICAN NATIONAL STANDARDS INSTITUTE - ANSI A208.1 (1999). Mat-formed wood particleboard: Specification. National Particleboard Association. Gaithersburg.

ASSOCIAÇÃO BRASILEIRA DE NORMAS TECNICAS. NBR 14810 - Chapas de madeira aglomerada - parte 3: Métodos de Ensaio, terminologia. Rio de Janeiro, 1999, 32p.

ASSOCIAÇÃO BRASILEIRA DE NORMAS TECNICAS. NBR 15575/2013 - Norma de Desempenho" - Edificaçóes Habitacionais.Rio de Janeiro, 2013.

BATTISTElle, R. A. G.; MARCILIO, C.; LAHR, F. A. R. Emprego do bagaço da cana-de-açúcar (Saccharum officinarum) e das folhas caulinares do bambu da espécie Dendrocalamus giganteus na produção de chapas de partículas. Revista Minerva, v 5, n.3, p.297-305, 2009.

BERTOLINI, S.M. et al..Emprego de resíduos de Pinus sp tratado com CCB e resina PU de mamona na produção de chapas de partículas. Capítulo 2. Painéis de Partícula de Madeira e de materiais lignocelulósicos / São Carlos: EESC/USP, 2013, 339 p. ISBN 97885802301922013.

BOND, D.A.; SMITH, P. A. Modelling the transport of low-molecular-weight penetrants within polymer matrix composites. Applied Mechanics Reviews, v. 59, p. 249-267, 2006.

BRAZOLIN,S. Biodeterioração, anatomia do lenho e análise de risco de queda de árvores de tipuana, Tipuana tipu (Benth.) O. Kuntze, nos passeios públicos da cidade de São Paulo, SP. 2009. 266f. Tese (Doutorado) - Escola Superior de Agricultura "Luiz de Queiroz", Universidade de São Paulo, Piracicaba, 2009.

BRITO, E.O.et al. Propriedades de chapas produzidas com resíduos do fruto de coco e partículas de pinus. Revista Floresta e Ambiente.v.11, n.2, p.01-06, 2004.

CAMPOS, C. I. Propriedades físico-mecânicas de MDF a partir de madeira de reflorestamento $e$ adesivos alternativos em diferentes teores. 2005. 102f. Tese (Doutorado) - Escola de Engenharia de São Carlos, Universidade de São Paulo, São Carlos, 2005.

CARASCHI, J. C.; LEÃO, A. L.; COIADO CHAMMA, P. V. Painéis produzidos a partir de resíduos sólidos para aplicação na arquitetura. Polímeros: Ciência e Tecnologia, São Carlos, v.19, n. 1, p. 47-53, 2009.

CONTRERAS, W. M. et al. Diseño de Tableros de Partículas de Caña Brava y Adhesivo Fenol - Formaldehído. Rev. For. Lat, n. 39, p. 39- 55, 2006. 
CREWDSON, M. Outdoor weathering must verify accelerated testing. Q-Lab Weathering $=$ Research Service 1005 SW 18th Avenue Homestead, FL 33034-1725 U.S.A mcrewdson@q-lab.com.2009 Acesso em: 25 jun. 2013.

DANIEL, G. F.; NILSSON, T. Developments in the study of soft rot and bacterial decay. In: BRUCE, A.; PALFREMAN, J. W. (Eds.) Forest Products Biotechnology. London:Taylor and Francis, p. 37-62, 1998.

EUROPEAN STANDARD EN 113:1996, Wood preservatives - Test method for determining the protective effectiveness against wood destroying basidiomycetes Determination of the toxic values. 1996, $34 \mathrm{p}$.

EUROPEAN COMMITTEE FOR STANDARDIZATION. European Standard. DIN EN 321 Wood-based panels. Determination of moisture resistance under cyclic test conditions. 2001, p. 1-7.

FABIYI, J. et al.. Wood plastic composites weathering: visual appearance and chemical changes. Polymer Degradation and Stability, p 93 (8)1405-14, 2008.

FIORELLI, J.et al. Particulate composite based on coconut fiber and castor oil polyurethane adhesive: An eco-efficient product. Industrial Crops and Products (Print), v. 40, p. 69-75, 2012.

FIORELLI, J. et al. Sugarcane bagasse and castor oil polyurethane adhesive-based particulate composite. Materials Research (São Carlos. Impresso), p. 01-08, 2013.

GATANI, M. et al. New Process for Peanut Husks Panels: Incorporation of Castor Oil Polyurethane Adhesive and Different Particle Sizes. Key Engineering Materials (Online), v. 600 , p. 452-459, 2014.

GARZON, N. et al. Durability evaluation of agroindustrial waste based particle boards using accelerated aging cycling tests. Key Engineering Materials, Pfaffikon, v. 517, p. 628634, 2012.

HAYASHI, T.; MIYATAKE, A.; HARADA, M. Outdoor exposure tests of structural laminated veneer lumber. Journal of Wood Science, v. 48, p.69-74, 2002.

INSTITUTO DE PESQUISAS TECNOLÓGICAS. Madeira: Uso sustentável na construção civil. Dados internacionais de catalogação na publicação (CIP), São Paulo, 2003.

INSTITUTO DE PESQUISAS TECNOLÓGICAS - IPT. Manual: Biodeterioração de madeiras em edifícios. São Paulo, 2001, p. 54.

IWAKIRI, S. Painéis de madeira reconstituida. Curitiba: FUPEF, 274 p. 2005.

JOHN, V.M.; AGOPYAN, V.; PRADO, T.A. Durabilidade de compósitos de cimento e fibras vegetais. Workshop: Durabilidade das construçôes. São Leopoldo/RS,1997, p 19-29.

KARLSSON, P.; MCNATT, J. D.; VERRILL, S. P. Vacuum-pressure soak plus ovendry as an accelerated-aging test for wood-based panel products. Forest Prod Journal, v. 46, p. 84-88, 1996. 
KOJIMA, Y.; SHIMODA, T.; SUZUKI, S. Modified method for evaluating weathering intensity using outdoor exposure tests on wood-based panels. J Wood Sci, v.58, p 525531,2012

KOJIMA, Y.; SUZUKI, S. Evaluating the durability of wood-based panels using internal bond strength results from accelerated aging treatments. Faculty of Agriculture, Shizuoka University, 836 Ohya, Suruga-ku, J Wood Sci, Japan, v. 57, p 7-13. 2010.

KOJIMA, Y.; SUZUKI, S. Evaluating the durability of wood-based panels using bending properties after accelerated aging treatments. Faculty of Agriculture, Shizuoka University, 836 Ohya, Suruga-ku, J Wood Sci, Japan, v. 57, p 126-133, 2011.

MADURWAR, M. V.; RALEGAONKAR, R. V.; MANDAVGANE, S. A. A review: Application of agro-waste for sustainable construction materials. Construction and Building Materials, v. 38, p. 872-878, 2013.

MALONEY, T.M. The family of wood composite materials. Forest Products Journal. v.46, n.2, p. 19-26. 1996.

MELO, R. R. Propriedades físico-mecânicas de painéis aglomerados produzidos com diferentes proporçóes de madeira e casca de arroz. Ciência Florestal, Santa Maria, v. 19, n. 3/4, p. 449-460, 2009.

MENDES, L. M.; ALBUQUERQUE, C. E. C.; IWAKIRI, S. Revista da Madeira Wood Magazine, Edição Especial - Painéis, p.12, 2003.

MENEZZI, S.C.H et al. Properties after weathering and decay resistance of a thermally modified wood structural board. International Biodeterioration \& Biodegradation, v 62, p. 448-454, 2008

MONTEIRO, M. B.; FREITAS, A. R. Método de ensaio acelerado para avaliação da durabilidade natural de madeiras. Revista Árvore, Viçosa, v.21, n.4, p.555-561, 1997.

MOREIRA, F. M. S.; SIQUEIRA, J. O. Microbiologia e bioquimica do solo. 2 ed. Lavras:UFLA, 2006. 729 p.

MORESCHI, J. C. Os causadores de danos a madeira. Revista da Madeira, Sao Paulo, v. 4, n. 24, p. 20-22, 1995.

OKUDA, O.; SATO, S. Bond durability of kenaf core binderless boards II: outdoor exposure test. J. Wood Sci. p. 54:36-44, 2008.

PABLO, A. A.; PEREZ, E. B.; ELLA, A. B. Development of particleboard on a pilotplant and semi-commercial scale using plantation and secondary wood species and agricultural fibrous waste materials. Forest Products Research and Industries Development Commission, University of the Philippines, Philippines, 1975.

PASSOS, P. R. A. Destinação sustentável de cascas de coco verde (Cocos nucifera): obtenção de telhas e chapas de partículas. 2005. 166f. Tese (Doutorado) - Instituto Alberto Luiz Coimbra de Pós-Graduação e Pesquisa de Engenharia (COPPE), Universidade Federal do Rio de Janeiro, UFRJ, Rio de Janeiro, 2005 
Q-LAB. Bulletin LL-9025.Outdoor Weathering: Basic Exposure Procedures.p 8.2011. Disponível em: <http://www.q-lab.com/resources/technical-bulletins.aspx>. Acesso em: 05 fev.2012.

SARTORI, D.; CRAVO, MACHADO J; N GARZON ; FIORELLI, J ; SAVASTANO JUNIOR H. Painel em Madeira de Reflorestamento e Chapas de Partículas para Instalaçóes Rurais. Floresta e Ambiente, v. 19, p. 171-178, 2012.

SCHEFFER T.C. Microbiological Degradation and the causal organisms. Chapter of book 2. Wood deterioration and its prevention by preservative treatments. v. 1 . Degradation and protection of wood. Darrel D. Nicholas, Editor. p. 31-105, 1973.

SEKINO, N. Outdoor and indoor exposure test of wood based panels. Wood Industry, v. 58, n.7, p. 298-304, 2003.

SILVA, S.A.M.; LAHR, FRANCISCO A.R.. Chapas de partículas confeccionadas com resíduos de madeiras tropicais de baixa densidade.Capítulo 14 do livro: Reciclagem de resíduos para a construção civil. Editora da Universidade FUMEC-DEA.P.343-365. Belo Horizonte - MG. 2008.

SILVA, M.S.A ; AZAMBUJA M; SEGANTINI, A.A. Avaliação da densidade aparente de chapas de madeira aglomerada confeccionadas com partículas de madeira tropical e poliuretana derivada de óleo de mamona. Capítulo 4. Painéis de Partícula de Madeira e de materiais lignocelulósicos / São Carlos EESC/USP, 2013, 339 p. ISBN 97885802301922013.

STARK, N. M. Effect of weathering cycle and manufacturing method on performance of wood flour and high-density polyethylene composites. Journal of Applied Polymer Science, v. 100, p.3131-3140, 2006.

STARK, N. M., MATUANA, L. M., CLEMONS, C. M. Effect of processing method on surface and weathering characteristics of wood-flour/HDPE composites. Journal of Applied Polymer Science, v. 93, p.1021-1030, 2004.

TANACA, H. K. et al. Discoloration and fungal growth on three fiber cement formulations exposed in urban, rural and coastal zones. Building and Environment, v. 46, p. 324-330, 2011.

VALARELLI I. de D. et al.. Avaliação do desempenho de painéis de partículas aglomeradas de bambu da espécie Dendrocalamus giganteus. Capitulo 8. Paineis de partículas de madeira e de materiais lignocelulósicos. São Carlos EESC/USP. P 145, 2013.

WIDYORINI, R.; XU, J.; UMEMURA, K., KAWAI, S Manufacture and properties of binderless particleboard from bagasse: effects of raw material type, storange methods and manufacturing process. Journal of wood science, v. 52, n. 6, p. 648-654, 2005.

YOUNGQUIST,J.A.Wood-bases Composites and panel products Forest Products Laboratory. Wood handbook-Wood as an engineering material. Gen. Tech. Rep. FPL-GTR-113. Madison, WI: U.S. Department of Agriculture, Forest Service. Forest Products Laboratory. 463 p.1999

ZENID, G. J. Madeiras e suas características. In: OLIVEIRA, J. T. S.; FIEDLER, N. C.; NOGUEIRA, M. (Eds.).Tecnologias aplicadas ao setor Madeireiro, Jerônimo Monteiro:Suprema Gráfica e Editora, p.125 -158, 2007. 